\title{
A study on combining global and regional climate model results for generating climate scenarios of temperature and precipitation for the Netherlands
}

\author{
G. Lenderink · A. van Ulden · B. van den Hurk • \\ F. Keller
}

Received: 27 June 2006/ Accepted: 2 January 2007/Published online: 10 March 2007

(C) Springer-Verlag 2007

\begin{abstract}
Climate scenarios for the Netherlands are constructed by combining information from global and regional climate models employing a simplified, conceptual framework of three sources (levels) of uncertainty impacting on predictions of the local climate. In this framework, the first level of uncertainty is determined by the global radiation balance, resulting in a range of the projected changes in the global mean temperature. On the regional $(1,000-5,000 \mathrm{~km})$ scale, the response of the atmospheric circulation determines the second important level of uncertainty. The third level of uncertainty, acting mainly on a local scale of 10 (and less) to $1,000 \mathrm{~km}$, is related to the small-scale processes, like for example those acting in atmospheric convection, clouds and atmospheric meso-scale circulations-processes that play an important role in extreme events which are highly relevant for society. Global climate models (GCMs) are the main tools to quantify the first two levels of uncertainty, while high resolution regional climate models (RCMs) are more suitable to quantify the third level. Along these lines, results of an ensemble of RCMs, driven by only two GCM boundaries and therefore spanning only a rather narrow range in future climate predictions, are rescaled to obtain a broader uncertainty range. The rescaling is done by first disentangling the climate change response in the RCM simulations into a part related to the circulation, and a residual part which is related to the global temperature rise. Second, these responses are
\end{abstract}

G. Lenderink $(\bowtie)$ · A. van Ulden · B. van den Hurk

F. Keller

Climate Research Department, KNMI,

PO Box 201, 3730 AE De Bilt, The Netherlands

e-mail: lenderin@knmi.nl rescaled using the range of the predictions of global temperature change and circulation change from five GCMs. These GCMs have been selected on their ability to simulate the present-day circulation, in particular over Europe. For the seasonal means, the rescaled RCM results obey the range in the GCM ensemble using a high and low emission scenario. Thus, the rescaled RCM results are consistent with the GCM results for the means, while adding information on the small scales and the extremes. The method can be interpreted as a combined statistical-dynamical downscaling approach, with the statistical relations based on regional model output.

\section{Introduction}

In recent years, there is an increasing demand from society for information on climate change with high spatial resolution. Since global climate models (GCMs) have a relatively low resolution (at present typically between 200 and $500 \mathrm{~km}$ ) they have obvious limitations to provide this information directly. In particular, this applies to indices related to the extremes, which are most relevant to society (Kunkel et al. 1999). Therefore, statistical and dynamical downscaling tools are used to fill this gap. In this study we focus on dynamical downscaling, in which high resolution regional climate models (RCMs) are used. These models are based on similar physical relations as GCMs, but now applied on high resolution (typically $20-50 \mathrm{~km}$ ) and a limited domain (typically $5,000 \times 5,000 \mathrm{~km}^{2}$ ). They are forced at their lateral boundaries by the 
output of the GCMs. Since they are based on physics they can at least in principle represent the complex interactions and feedbacks involved with climate change. However, like GCMs, they may contain (systematic) errors and they are computationally expensive.

Regional models add two different types of smallscale information to the GCMs results. First, they add information on the local conditions at specific locations. This is typically important when large horizontal gradients occur, for example related to the topography or the coastline. Second, they add information on processes that are small scale but which are not necessarily tied to a specific location, like for example frontal systems, small-scale convective precipitation, and other meso-scale phenomena.

In a recently completed project PRUDENCE (Christensen et al. 2002), a significant number of RCM simulations for Europe have been carried out with ten different state of the art RCMs. Despite that several GCM boundary conditions were available, integrations with the total ensemble of RCMs has been carried out for only one GCM boundary condition, HadAM3H driven by A2 emissions. Déqué et al. (2007) showed that, in general, for the seasonal means of precipitation and temperature the spread between different RCMs forced by the same boundaries is small compared to the spread due to the difference in GCM boundary condition. But, differences in the RCM physics may strongly impact on the extremes, for example on daily temperature extremes as shown by Kjellström et al. (2007).

Figure 1 shows the seasonal mean precipitation change in summer for the Netherlands in an RCM ensemble driven by the HadAM3H model (A2 emissions) in comparison with an ensemble of five selected GCMs driven by two emission scenarios (A1b and B1) (see Sect. 2 for details on these model integrations and on why we selected these GCMs). Clearly these RCM results cannot be used directly to produce scenarios that represent the range of outcomes based on the GCM knowledge. On the other hand, the GCM ensemble may be used for the means, but they are not suitable for scenarios of small-scale extremes.

One may question what causes the differences between the RCM and GCM ensemble in Fig. 1. The spread in the RCM ensemble is caused by the different representations of the small-scale physics and dynamics in the RCMs. The spread is strongly constrained by the GCM boundary that is imposed (Déqué et al. 2007). On the other hand, major contributors to the spread in the GCM ensemble are the differences in emission scenario, climate sensitivity and the response of the large-scale dynamics. The first two factors act on a global scale, whereas the large-scale dynamics have a strong impact on the regional climate. Van Ulden and van Oldenborgh (2006) (hereafter, UO06) show that the greater part of the drying in summer projected by these GCMs for western Europe can be explained by a circulation change with more easterly winds.

Thus, as illustrated in Fig. 1, the outcome of a limited number of RCM simulations using only few GCM boundaries (models and emission scenarios) does not provide a realistic representation of the range of possible future climate conditions. In this paper, with uncertainty (range) we refer to the spread in the outcome of climate model simulations, since in many respects models represent our best cumulated knowledge of the climate system. [Uncertainty is used in a Bayesian sense; that is, uncertainty refers to the current knowledge. The actual uncertainty in the evolution of the climate system cannot be determined as discussed e.g. in Dessai and Hulme (2003).] More specifically, we refer to the range that we would have
Fig. 1 Change in mean winter and summer precipitation between 20712100 and 1961-1990 in an ensemble of GCM simulations and RCM simulations (see text for details). Rank denotes the relative order (between 0 and 1) of the sorted results
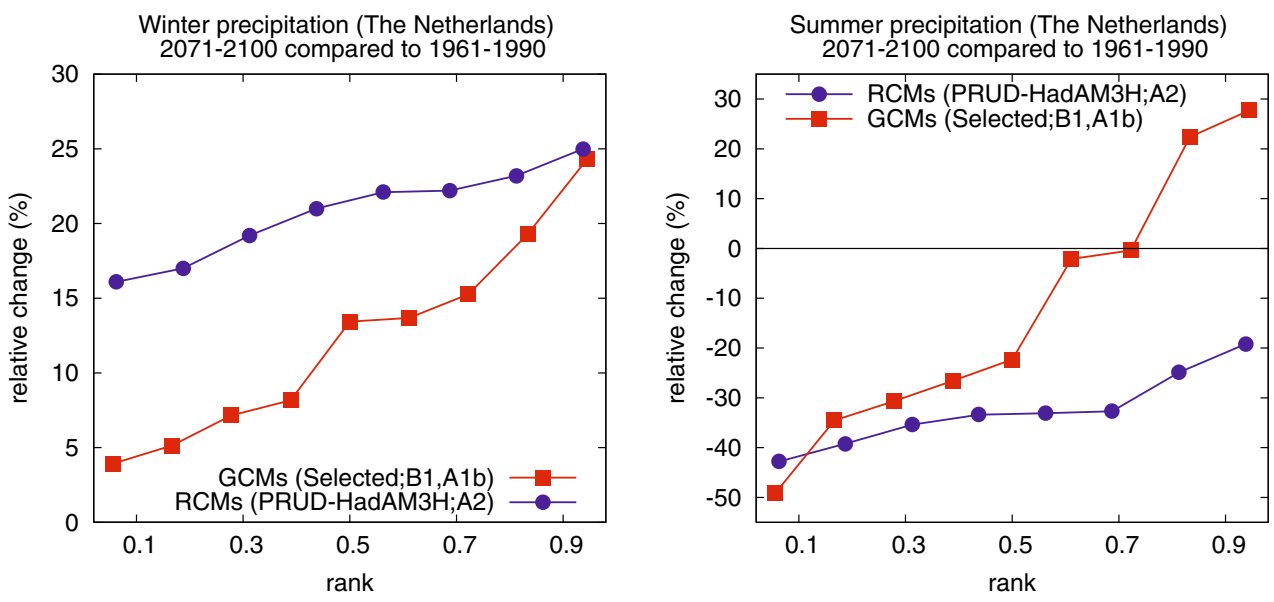
obtained when downscaling the integrations of the selected GCMs with our set of RCMs. We note that these RCM integrations are presently not available, and that they are computationally too expensive to be made available soon. However, in the European FP-6 project ENSEMBLES (Hewitt and Griggs 2004), many of these will be carried out.

In this study we aim to combine information from the GCMs and the RCMs to produce a set of scenarios for the Netherlands that give a plausible representation of the uncertainty range. Facing the fact that we are dealing with rather limited information, in particular from the RCMs, this is obviously not a trivial task. Even using our constrained definition of uncertainty range, we cannot quantify the range precisely since the $\mathrm{RCM}$ integrations that are needed have not been carried out. But, one important condition is that the set of scenarios should represent the major part of the spread in the selected GCM results with respect to the seasonal mean changes (as shown in Sect. 5.4).

The scenarios are produced by a rescaling technique of the RCM results, using global mean temperature and an index of the circulation as scaling parameters (see Sect. 3 for an overview of the method). In the literature, global mean temperature is often used as a scaling parameter in so-called pattern-scaling techniques (see e.g. Dessai et al. 2005). We add circulation as a second important scaling parameter. In Sect. 4, a decomposition of the response in the regional model simulations into a part related to the circulation change and a residual change (related to the global temperature rise) is performed. The method of decomposition closely follows the work by UO06, but we apply it to RCM results (instead of GCM results) and to a much wider range of climate indices. In UO06 the decomposition is mainly a model diagnostic; we go further by actually using these components to construct scenarios by the rescaling technique. The actual rescaling, scenario production and a cross validation with GCM results (for the seasonal means) is done in Sect. 5. A summary and conclusions are given in Sect. 6 .

\section{Data}

\subsection{Regional model data}

We used output of regional climate model simulations performed in the PRUDENCE project. Details on this project and on the model integration setup can be found in Christensen and Christensen (2007). In this study we used output of eight of these RCMs: HIRHAM, CHRM, CLM, HadRM3H, RegCM, RAC-
MO2, REMO, and RCAO. RCM integrations are available for 30-year time slices of the period 19611990 (control) and 2071-2100 (future).

For the RCMs we only considered an A2 emission scenario because it has a large response and therefore a (relatively) good signal-to-noise ratio. This implies that scenarios for other greenhouse gas emissions can be constructed by interpolation, rather than extrapolation. With the A2 emission scenario integrations using HadAM3H boundaries are available for all RCMs. Integrations using ECHAM4 boundaries are available for only two RCMs: RCAO and HIRHAM. We note that two different integrations of the ECHAM4 model are used to drive these RCM integrations (Christensen and Christensen 2007). Therefore, the change in the circulation in the RCAO integration differs from the HIRHAM integration. The RCMs use similar, but not the same, computational grids with a typical grid size of $50 \times 50 \mathrm{~km}^{2}$ and a domain size of $5,000 \times 5,000 \mathrm{~km}^{2}$.

For temperature, large contrasts between land and sea jeopardize the direct use of GCMs data for coastal areas like the Netherlands; these models do not resolve these contrasts and may suffer from large horizontal numerical diffusion across the coastline. We use the RCM output of four grid boxes $\left(100 \times 100 \mathrm{~km}^{2}\right)$ located southeastward of De Bilt $\left(51-52^{\circ} \mathrm{N}, 5-6^{\circ} \mathrm{E}\right)$. This area, labeled with $A_{\mathrm{DB}}$, is chosen such that it is more than two grid points away from the coast, which minimizes possible errors resulting from (numerical) diffusion across the coastline, while still being representative for the central Netherlands (Fig. 2).

For precipitation, we used a larger area $A_{\mathrm{CEN}}$ of $11 \times 11$ grid points $\left(500 \times 500 \mathrm{~km}^{2}\right)$ as shown in Fig. 2 .

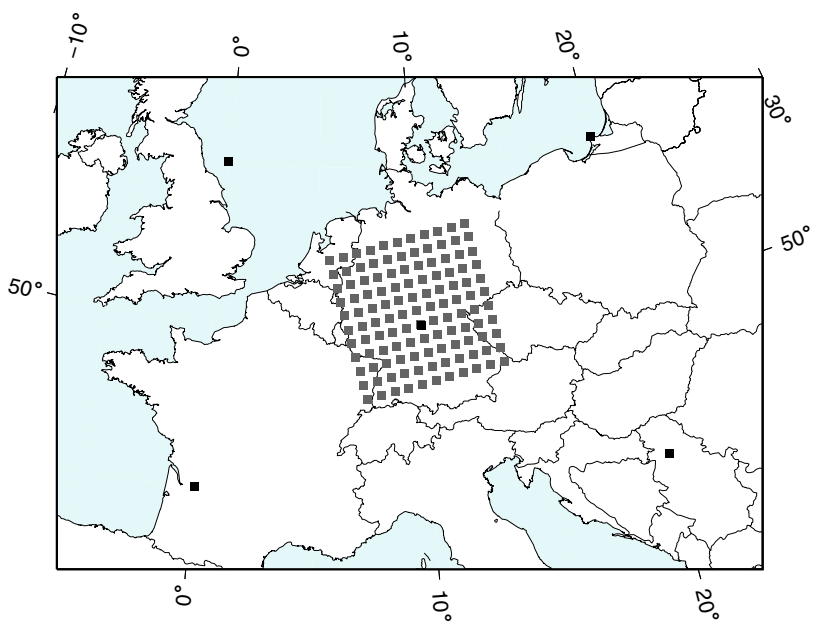

Fig. 2 The area $A_{\mathrm{CEN}}$ used in the RCM downscaling for precipitation (grey squares). The area used for temperature $A_{\mathrm{DB}}$ (close to De Bilt) is given by the upper-left four grid-points. Black squares are used for the mean sea level pressure 
The area has to be large in order to obtain sufficient signal-to-noise ratio for precipitation extremes. The increase in the number of samples (the statistics) has been established by the commonly used technique of pooling data of the individual grid points. We note that for the separation procedure we have to compute extremes from yearly and 10-year seasonal data. Additionally, the precipitation change in the large area has to be representative for the Netherlands. This implies that the area is sufficiently far away from major seas, like the Baltic sea, and from areas with major orography like the Alps. Obviously, these conditions are not fully compatible when precipitation gradients occur, and the choice of the area represents a compromise. Since the extreme precipitation statistics might be dominated by specific areas with high precipitation amounts, we performed the analysis also on the data corrected for the spatial differences. This was done on a monthly basis by multiplying the local precipitation time series with the area $\left(A_{\mathrm{CEN}}\right)$ mean precipitation divided by the local mean precipitation. Differences between both analysis turned out to be negligible, and therefore we only show the results for the uncorrected data.

\subsection{Global model data}

Output of five GCMs for the IPCC 4th assessment report (AR4) is used: HadGEM, MIROCHi, GFDL2.1, CCC63, and ECHAM5 (see UO06 for details about these models). These models have been selected in UO06 based on their ability to reproduce the atmospheric circulation on the global and on the European scale. Different ensemble simulations and different greenhouse gas emission scenarios (A2, A1B and B1) are employed. Spatial maps of the changes in Europe, and more quantitatively, the output of the GCMs interpolated to the southeastern part of the Netherlands $\left(51^{\circ} \mathrm{N}, 6^{\circ} \mathrm{E}\right)$ are considered. Surface pressure at 5 different locations are used to compute indices of the circulation (see Fig. 2).

\subsection{Climate scenario indices}

The change in the following climate indices $Q$ is estimated with the downscaling: the mean temperature $T_{\mathrm{m}}$ and the 10th, 50th and 90th percentiles of daily mean temperatures, $T_{10}, T_{50}$ and $T_{90}$, respectively, and the mean precipitation $P_{\mathrm{m}}$, the mean on a wet-day $P_{\mathrm{wd}}$, the wet-day frequency $f_{\mathrm{wd}}$, and the 99th percentile of daily wet-day precipitation $P_{99 \mathrm{wd}}$. A wetday is defined as a day with precipitation amounts exceeding $0.1 \mathrm{~mm}$. These climate indices are com- puted for both the summer season JJA and the winter season DJF.

\section{Outline scenario production}

\subsection{Conceptual framework}

Our conceptual framework (see Fig 3) borrows from the ideas described in Giorgi (2005a) in which an excellent overview of the nature of regional climate prediction and associated uncertainties is presented. It is based on a highly simplified description of the response of the climate system to enhanced greenhouse gas concentrations in terms of first, second, and third order responses. The different scales, from global to local, are plotted along the $x$-axis, and along the $y$-axis a measure of the uncertainty range is plotted. The main physical processes are shown in the top box. The uncertainty in the representation of these processes in the models (second box) are responsible for uncertainty in the predictions.

In our conceptual framework, the main uncertainty on the global scale is the response of the global radiation balance to enhanced greenhouse gas concentrations. This is determined by the greenhouse gas emission scenarios (Nakicenovic et al. 2000) which can be interpreted as a forcing. In addition, the climate sensitivity-commonly defined by the response of the global temperature to $\mathrm{CO}_{2}$ doubling (Houghton et al. 2001) - plays an important role. The climate sensitivity

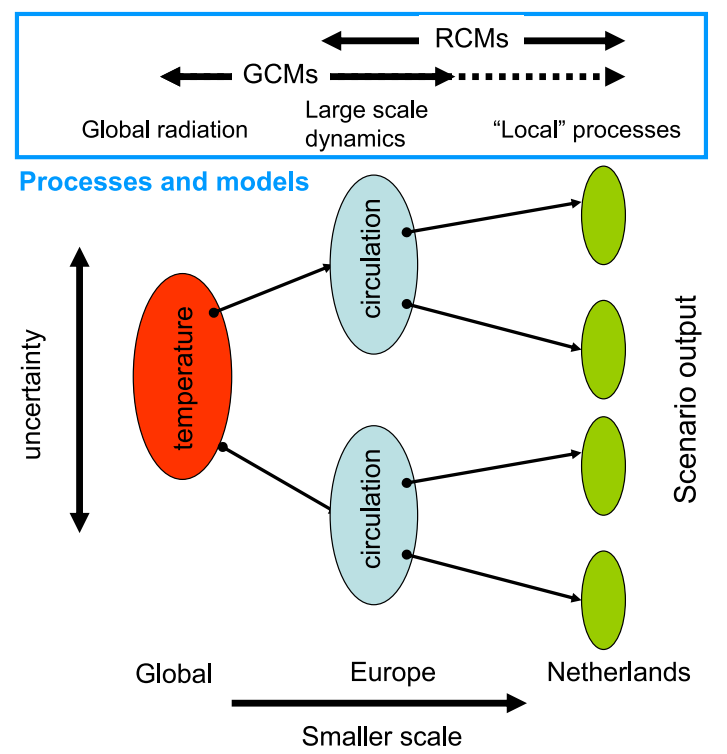

Fig. 3 Conceptual framework of the climate system (see text for details) 
is strongly influenced by feedbacks through clouds, atmospheric stability, water vapor and surface albedo-see Bony et al. (2006) for a recent overview of these feedbacks. The range in global temperature increase that results from the forcing and the climate sensitivity for the used GCMs runs in this paper is shown in Fig. 10.

On the European scale, the change in large-scale atmospheric circulation is a second main source of uncertainty (Emori and Brown 2005; UO06). UO06 made a decomposition of the precipitation change of the selected GCMs into a part related to the circulation change and a residual part. They showed that for the difference in summer precipitation between the future period 2060-2100 and the control period 1960-2000 about two third can be explained by the change in circulation.

At a smaller scale, for example for central Europe or the Netherlands, the uncertainty in the representations of the small-scale physical processes play an important role. Examples of these processes are small-scale convection, meso-scale circulations, and fine scale interactions with the dynamics and orography or land-sea transitions. These small-scale processes may strongly impact on the extremes, and this is the area where the RCMs potentially add useful climate information.

Figure 3 is obviously a strongly simplified view of the climate system, in particular related to propagation of uncertainty which is assumed to occur mainly from the larger scale to the smaller scale. With this approach we do not want to imply that the small scales do not influence the larger scales. For example, the representation of summertime convective precipitation at the smallest scale may relate to continental drying, which may impact on the large-scale flow dynamics. Further, Murphy et al. (2004) showed a significant spread in the climate sensitivity acting on the global scale due to uncertainty in the representation of the unresolved small-scale processes. The problem with large-scale errors is that they cannot be removed using regional models or statistical downscaling.

\subsection{Overview of the downscaling method}

The downscaling procedure consists of a linear rescaling of results of the available set of the RCM simulations using two steering parameters: the global temperature change $\Delta T_{\mathrm{g}}$ and the change in the geostrophic west wind $\Delta G_{\mathrm{w}}$ (see Appendix A and Sect. 4.2 for details on this circulation index). In accordance, we write the change in the climate index $\Delta Q$ between the control and the future period as
$\Delta Q=c_{\mathrm{Q}}^{\mathrm{T}} \Delta T_{\mathrm{g}}+c_{\mathrm{Q}}^{\mathrm{circ}} \Delta G_{\mathrm{w}}$

with $c_{\mathrm{Q}}^{\mathrm{T}}$ and $c_{\mathrm{Q}}^{\text {circ }}$ determined by the available $\mathrm{RCM}$ simulations:

$c_{\mathrm{Q}}^{\mathrm{T}}=\left[\frac{\Delta Q_{\mathrm{r}}^{*}}{\Delta T_{\mathrm{g}}^{*}}\right]$

$c_{\mathrm{Q}}^{\mathrm{circ}}=\left[\frac{\Delta Q_{\mathrm{c}}^{*}}{\Delta G_{\mathrm{w}}^{*}}\right]$

Here $\Delta T_{\mathrm{g}}^{*}$ is the global temperature rise in the GCM that is used to force the RCM simulation, and $\Delta G_{\mathrm{w}}^{*}$ is the circulation change in the RCM simulation. The circulation change in the RCM is in general rather close to circulation change imposed by the GCM boundary, but in some RCMs significant deviations occur in particular in summer (Van Ulden et al. 2007). The terms $\Delta Q_{\mathrm{c}}^{*}$ and $\Delta Q_{\mathrm{r}}^{*}$ are determined by a separation of the response in $Q$ between the control and the future time slice into a part related to the circulation change and a residual part. The residual part $\Delta Q_{\mathrm{r}}^{*}$ is an estimate of the change in $Q$ when the circulation would not have changed. We assume that it can be scaled with the global temperature change. The separation method is similar to the method in UO06 and details are described in Sect. 4. Finally, square brackets denote a weighted average of the different RCM results. In Sect. 5 four scenarios are produced by employing Eqs.1-3 combined with:

1. the steering parameters $\Delta T_{\mathrm{g}}$ and $\Delta G_{\mathrm{w}}$. These connect with the first two levels of uncertainty in our conceptual framework.

2. the weights of the different RCM simulations, yielding different values for $c_{\mathrm{Q}}^{\mathrm{T}}$ and $c_{\mathrm{Q}}^{\text {circ }}$. This explicitly accounts for the uncertainty in the representation of the small-scale physics; that is, the third level of uncertainty in Fig. 3.

\section{Scaling relations from the $\mathrm{RCM}$ results}

\subsection{Outline separation procedure}

The separation procedure (see Fig. 4) to decompose the response in $Q$ into a part related to the circulation change and a residual part consists of two steps, which essentially follow the procedure in UO06. This is done for both seasons considered. In the following we omit the reference to a season to keep the text concise. Thus, a 30-year average refers to a 30-year average for a particular season. First, the dependency of the 
climate indices $Q$ on the average flow conditions $G_{\mathrm{w}}$ is estimated for both the control and the future time slice. Second, using these estimated dependencies (the blue and red lines in Fig. 4) the change in $Q$ between the control and the future time slice is decomposed into a part related to the circulation change and a residual part. The residual change can be interpreted as the offset between the lines; that is, the change in $Q$ that would occur when there is no change in the circulation index. The slope multiplied by $\Delta G_{\mathrm{w}}$ is the change in $Q$ due to the circulation change.

Both steps are not straightforward. In the first step, we are interested in a change in $Q$ for a 30-year climatological period when the average flow conditions would change by a certain amount. Since we only have one 30-year time series this cannot be determined, and this dependency has to be inferred from variations on shorter time scales. Using the inter annual variability, $Q$ and the mean of the flow index $G_{\mathrm{w}}$ are computed for each year, and a linear regression is performed using a least-square fitting procedure. In addition, we computed two estimates based on 10-year binned data (similar to a group regression procedure). Details on these three regression methods are presented in Appendix B.

In the second step, when the regression lines of the control and the future period are not parallel, the offset between the two lines is not constant, but depends on the choice of $G_{\mathrm{w}, \text { ref }}$ in Fig. 4. To quantify this effect we chose two values of $G_{\mathrm{w}, \mathrm{ref}}$, one closer to the mean circulation of the control and the other closer to the mean of the future period (see Appendix C for details).

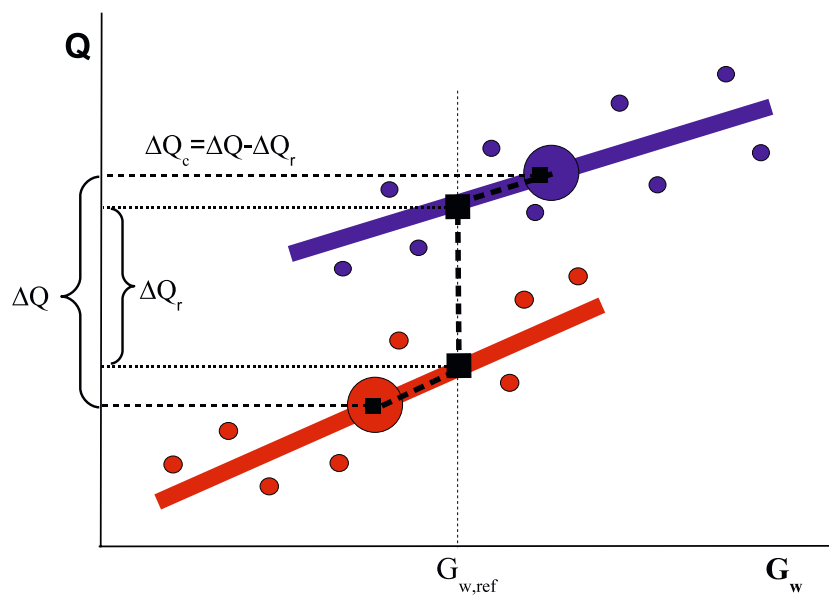

Fig. 4 Schematic representation of the regression lines estimated for the control (blue) and future (red) time slice, and the decomposition of the total change $\Delta Q$ into a part related to circulation change $\left(\Delta Q_{\mathrm{c}}\right)$ and a residual part $\left(\Delta Q_{\mathrm{r}}\right)$ (see Appendix C)
For each regional model simulation, the procedure described above gives six estimates (three regression methods times two splitting procedures) of the circulation dependent and residual changes. The spread in these estimates give a crude quantification of the uncertainty involved with the separation procedure. Given our application of constructing climate scenarios, with the whole chain of uncertainties involved, some of them which are extremely hard or impossible to quantify in a statistical sense (see e.g. Dessai et al. 2003), we do not attempt here to give statistical uncertainty bounds for the separation method. Furthermore, while this may be possible for the first step in the separation procedure, we do not think it is possible for the second step.

\subsection{The circulation index}

Figure 5 shows the relation between $G_{\mathrm{w}}$ and mean temperature and mean precipitation for De Bilt using data from 1911 to 2000 . $G_{\mathrm{w}}$ is computed from the ADVICE pressure data (Jones et al. 1999). For the yearly seasonal data explained variances are $50-70 \%$ for temperature and $20-40 \%$ for precipitation. However, binning the seasonal data in 10-year periods based on $G_{\mathrm{w}}$, the explained variance increases to $80-95 \%$ for both temperature and precipitation.

Figure 6 shows a comparison between the regression coefficients for the RCM simulations and the observations. The observations are divided in three 30 -year periods in order to give an impression of the natural variability on a 30 -year time scale. For winter, results with RACMO2 driven by ERA40 are in good agreement with the observations. However, the RCM simulations driven by the global climate model boundaries (HadAM3H and ECHAM4) show a too weak dependency of mean temperature on $G_{\mathrm{w}}$ and a too strong dependency of mean precipitation. For summer the RACMO2 ERA40 integration has a too weak dependency of precipitation. The results of scenario integrations for the control period, however, are within the observed range.

Considering the climate change signal, the circulation dependency increases in summer from the control to the future period. Assuming that the inter annual variability of the circulation remains constant, changes of the inter annual variability in mean precipitation and mean temperature scale with the changes in the slopes. Under these assumptions, the results indicate a small increase in inter annual variability of precipitation and a substantially increase $(+25 \%$ for the ensemble) for temperature. 

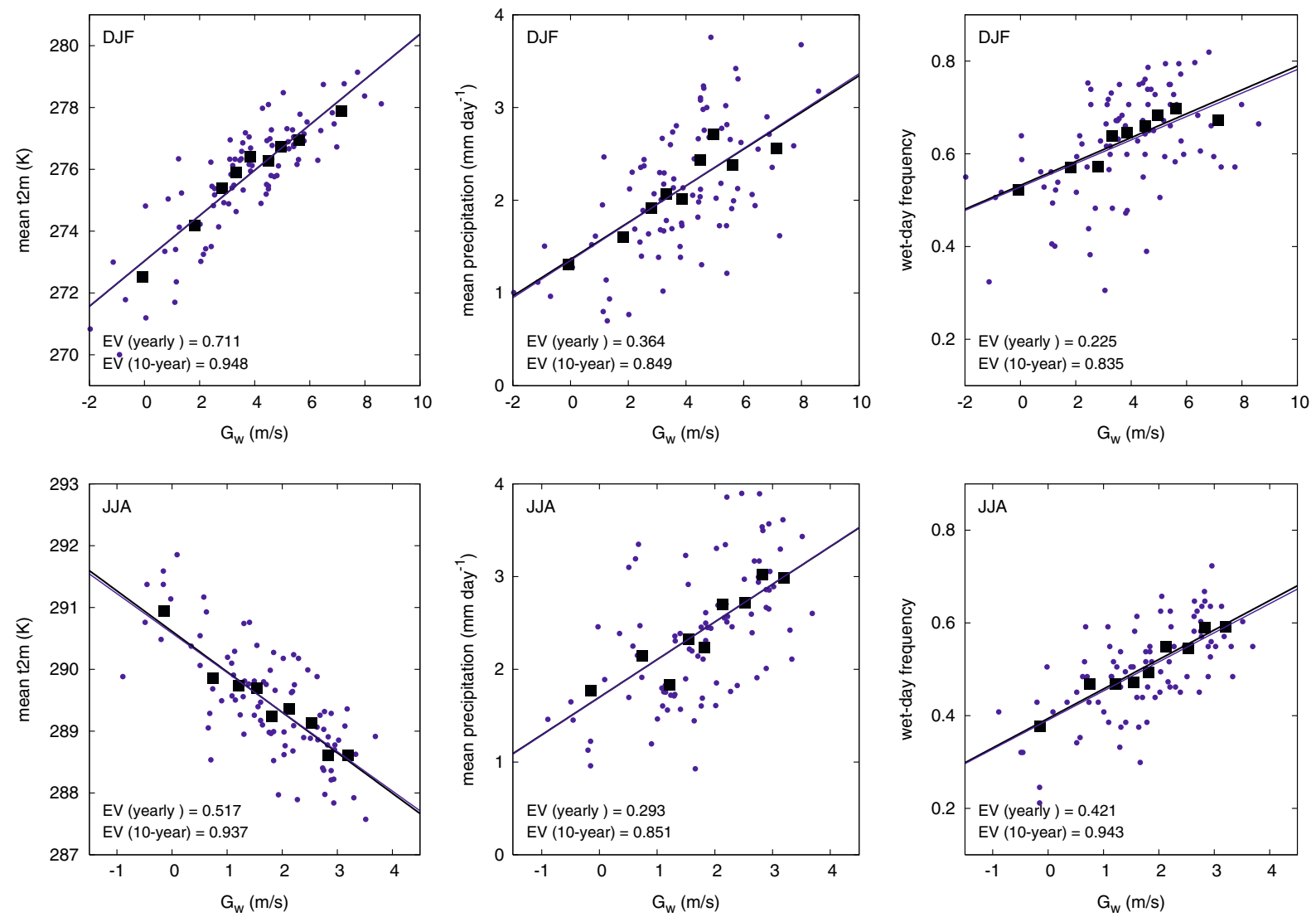

Fig. 5 Mean precipitation and mean temperature at De Bilt against $G_{\mathrm{w}}$ for the period 1911-2000. Shown are the individual years (small dots) and 10-year binned data based on $G_{\mathrm{w}}$ (large

\subsection{Separation in the case of summertime precipitation}

Detailed results of the separation procedure are illustrated for summer precipitation. Summer season is particularly interesting since the spread in both the GCM results and RCM results (even when forced with the same GCM boundaries) is large (Déqué et al. 2007; Lenderink et al. 2007). An interesting feature for summer precipitation is that recent RCM integrations show that despite the decrease in mean summer precipitation, the daily extremes might actually increase (Christensen and Christensen 2003).

Figure 7 shows the dependency on $G_{\mathrm{w}}$ of four different climate indices for precipitation: $P_{\mathrm{m}}, P_{\mathrm{wd}}, f_{\mathrm{wd}}$, and $P_{99 \mathrm{wd}}$. Results are shown for RACMO2 for both control and future simulation, and the observations of the CHR data base for 1961-1990 (Van den Hurk et al. 2005). These consists of precipitation measurements in 119 sub-catchments (average size approx. 1,000 $\mathrm{km}^{2}$ ) of the Rhine catchment area between Lobith (at the German-Dutch border) and Rheinfelden (at the Swiss-German border). We note that model data are squares). Also shown are the linear fits to the data and the explained variance $(E V)$

obtained for $A_{\mathrm{CEN}}$ which is larger than the catchment area. Inspection of the RACMO2 results showed that in general differences in the precipitation statistics between $A_{\mathrm{CEN}}$ and the Rhine catchment area are small.

The increase of the mean precipitation with $G_{\mathrm{w}}$ (Fig. 7a) is well represented by the regional model. Figure $7 \mathrm{~b}$, c shows the contribution of precipitation on a wet-day $P_{\mathrm{wd}}$, and the contribution of the change in wet-day frequency $f_{\mathrm{wd}}$. The interesting result is that the change in mean precipitation can be explained for the largest part by changes in the wet-day frequency; the mean precipitation on a wet-day is only slightly affected by the circulation. Even stronger, the extreme precipitation on a wet-day $P_{99 \mathrm{wd}}$ is not affected by the seasonal mean circulation. Most RCMs follow these rules, although in general most models have slightly larger dependency on the circulation in $P_{\mathrm{wd}}$ and $P_{99 \mathrm{wd}}$.

Since $P_{\mathrm{wd}}$ and $P_{99 \mathrm{wd}}$ have a small dependency on the circulation, the contribution of the residual change can be estimated relatively well. For the wet-day frequency, and consequently, the mean precipitation the 
Fig. 6 Slope of the regression lines of mean precipitation and mean temperature against strength of $G_{\mathrm{w}}$ for winter (DJF upper panels) and summer (JJA lower panels). Observations for De Bilt are shown for four different 30-year periods. Model results are shown for RACMO using ERA40 (only 1961-1990 period), RACMO using $\operatorname{HadAM} 3 \mathrm{H}$, and the model ensembles as defined in Table 2 (blue control; red future). Error bands denote the 25 th and 75 th percentiles of the total number of estimates ( 3 per model/ observation as discussed in Appendix B)
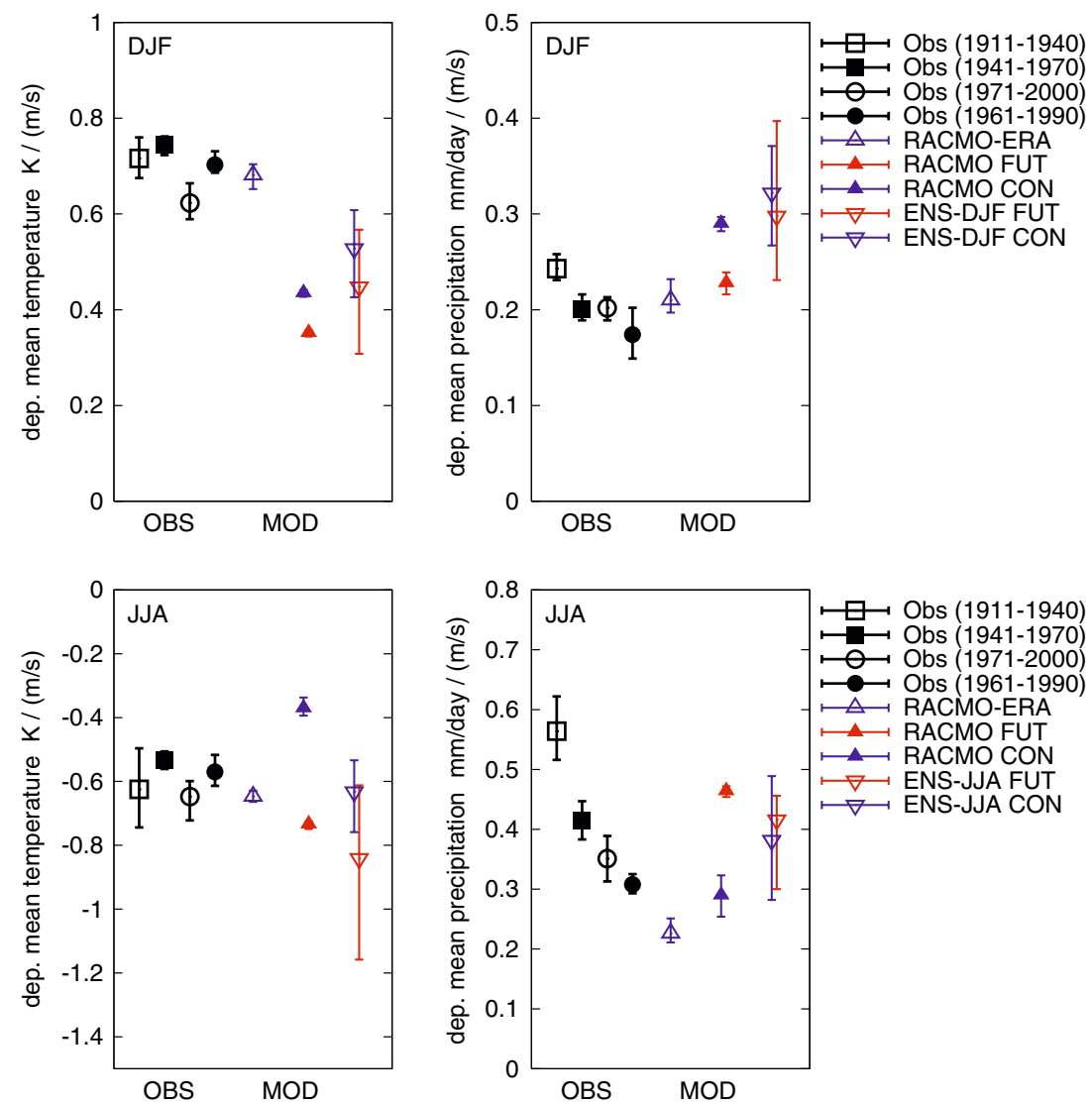

estimation is more difficult. For the wet-day frequency, it is shown that the slopes of the fits for the present and future time slice are different. Although this is not a property of all RCM results, most (5 out of 8) RCMs display this behavior. This may be a consequence of the continental drying between the control and future time slice, which enhances the land-sea contrasts. RACMO2 is rather moist in the present-day climate, but dries out considerably, although perhaps not as strong as most RCMs, from the control to the future integration (see Lenderink et al. 2007; Vidale et al. 2007).

Figure 8 shows the circulation dependent and residual changes for the same climate indices for the eight RCMs driven by HadAM3H boundaries. For each set of model simulations, six estimates are plotted. It is shown that, for one model, the results basically follow the diagonal line, representing a constant sum of circulation dependent and residual changes. Shown is a rather large spread for the mean precipitation. This spread is largely caused by the spread in the wet-day frequency. For wet-day frequency it is also clear that the assumption of the reference value of the circulation, $G_{\mathrm{w}, \text { ref }}$ in Fig. 4 , has a considerable impact on the separation. But we note that in general most of the spread in Fig. 8 originates from the differences between the RCMs.

\subsection{Scaling relations}

Figure 9 shows the scaling relations $c_{\mathrm{Q}}^{\mathrm{T}}$ and $c_{\mathrm{Q}}^{\text {circ }}$ defined by Eqs. 2 and 3 for the RCM ensemble driven by HadAM $3 \mathrm{H}$ boundaries. In addition to the data of the individual model integrations, we also plotted the average of the model ensemble, and the 10th, 20th, 80th and 90th percentiles as a measure of the spread in the RCM ensemble.

The change in mean precipitation in summer is highly sensitive to the circulation change; $c_{\mathrm{Q}}^{\text {circ }}$ is between 8 and $17 \%$ per $1 \mathrm{~ms}^{-1}$ change in $G_{\mathrm{w}}$. Most of this sensitivity can be explained by the sensitivity of the change in the wet-day frequency to the circulation. The residual part $c_{\mathrm{Q}}^{\mathrm{T}}$ of the change in the mean precipitation is small, between -5 and $+2 \%$ per degree global temperature rise. A slight reduction of the residual mean precipitation is due to the wet-day frequency. In all models $c_{\mathrm{Q}}^{\mathrm{T}}$ is positive for the change in mean precipitation on a wet-day.

For temperature extremes, the 10th percentile of daily temperature (cold days) increase with $0.8^{\circ} \mathrm{C}$ per 
Fig. 7 Dependency of $P, P_{\mathrm{wd}}$, $f_{\mathrm{wd}}$ and $P_{99 \mathrm{wd}}$ against $G_{\mathrm{w}}$ for the CHR observations (black), and the RACMO2 control (blue) and future (red) simulation. Shown are the fits to the seasonal yearly data (method 1$)$, the data binned in 10-year periods (big triangles) and the resampled 10-year surrogate climates (small dots) as discussed in Appendix B
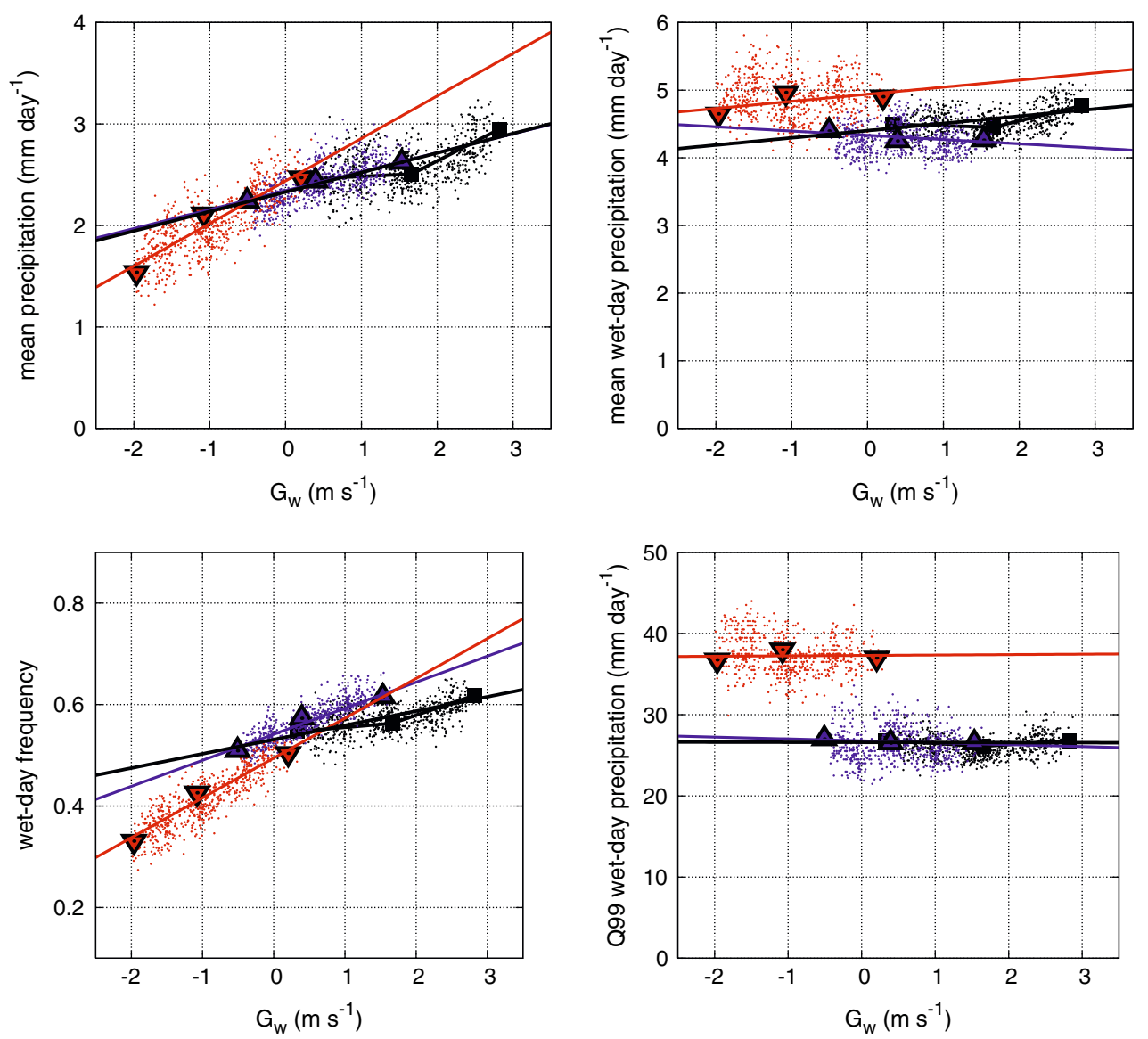

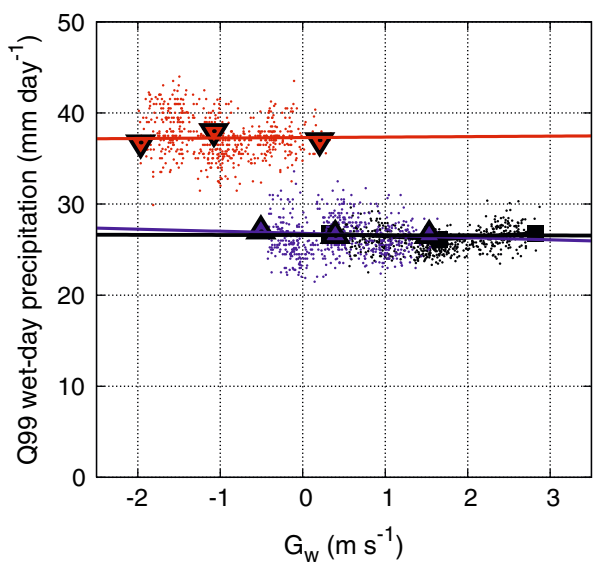

degree global warming. The lag of the local temperature rise compared to the global mean temperature rise is most likely caused by the relatively cold sea surface temperature in the $\operatorname{HadAM} 3 \mathrm{H}$ boundaries. The spread in the RCM results is very small, which may be related to the fact that cold days are dominated by westerly flows with a strongly control of the SSTs and western boundary prescribed by HadAM3H. For the 90th percentile of daily temperature, the spread in the RCM ensemble is much larger, most likely due to differences in the modeling of the hydrological cycle in the RCMs. There is a strong contribution of the circulation to the change; a reduction of $1 \mathrm{~ms}^{-1}$ adds on average $1.2^{\circ} \mathrm{C}$ to the change in the 90th percentile.

For some climate indices, for example for the mean precipitation, the RCM results scatter rather evenly around the computed mean. However, for other indices, for example for the 99th percentiles of daily precipitation, there appears to be a clustering of the RCM results in two groups and the average behavior is not supported by any of the individual model results. In this case, it makes sense to subdivide the ensemble into two groups, one with a high value of $c_{\mathrm{Q}}^{\mathrm{T}}$ and one with a low value of $c_{\mathrm{Q}}^{\mathrm{T}}$. This will be explored in the next section when constructing the scenarios.

\section{Climate scenarios for the Netherlands}

The downscaling tool described in the previous sections is employed to produce four climate scenarios for the Netherlands. They will be constructed for the change between the reference climate of 1990 (period 1976-2005) and 2050 (period 2036-2065). The choice of the time period and the number of scenarios has been made in consultation with the Dutch policy makers. Scenarios are constructed for two values of the global temperature rise, combined with two values of the circulation change (weak and strong). Earlier climate scenarios for the Netherlands (WB21, Kors et al. 2000) have only been constructed using the global temperature rise as a steering parameter, and have neglected effects of the circulation change. Thus, in the new scenarios the effect of circulation change as an important source of uncertainty for the future climate of the Netherlands is added. In addition, the present scenarios add more information on temperature 

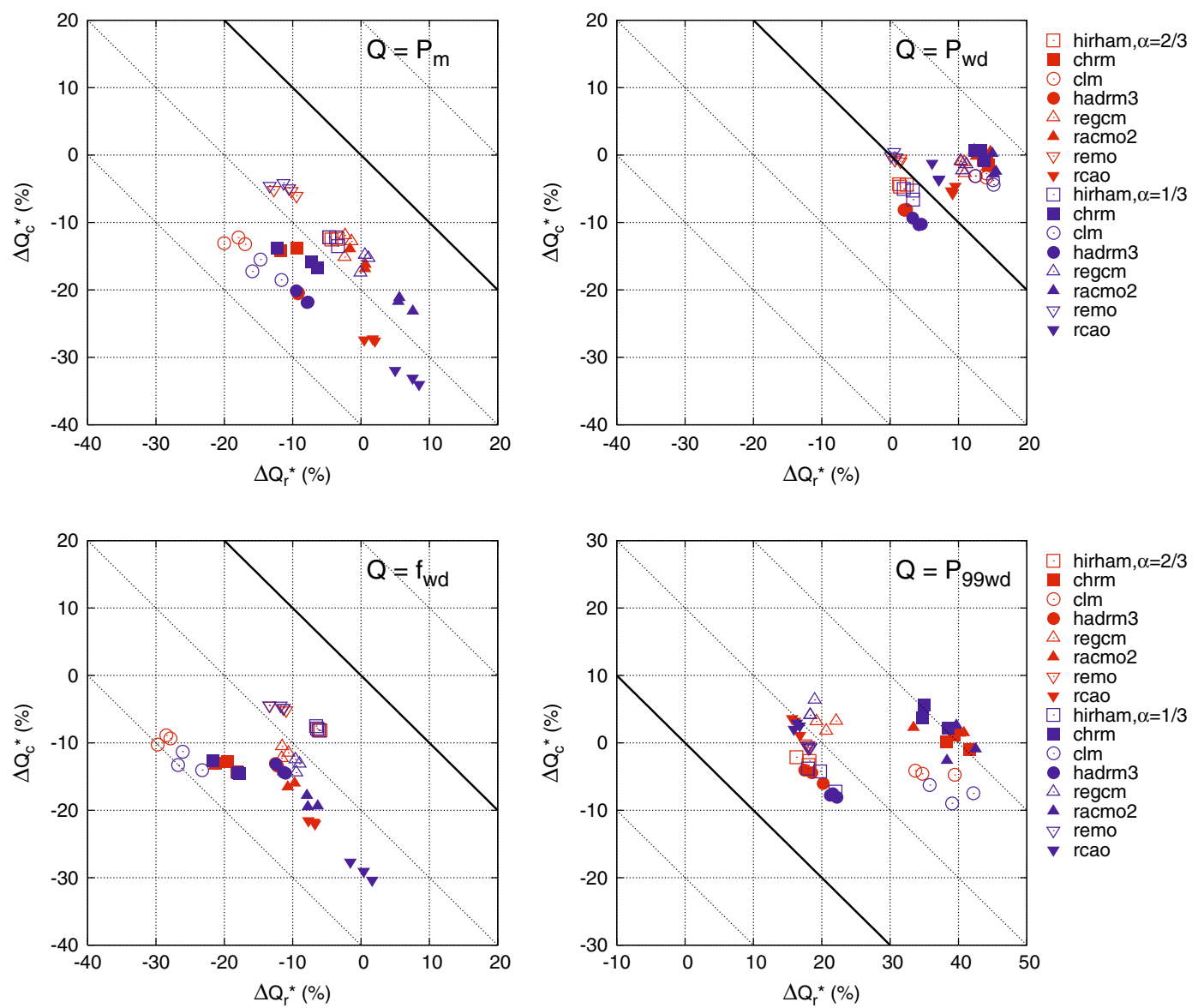

Fig. 8 Circulation dependent change $\left(\Delta Q_{\mathrm{c}}^{*}\right)$ and residual change $\left(\Delta Q_{\mathrm{r}}^{*}\right)$ determined for eight RCMs driven by $\mathrm{HadAM} 3 \mathrm{H}$ boundaries. Each different symbol (open circle, closed circle,

extremes compared to the WB21 scenarios, which were mostly focused on precipitation.

\subsection{Procedure}

The downscaling tool can be used in two different ways as described below. The straightforward use is to determine the input steering parameters in an objective way from the GCM results. For example, one might choose the 20th and 80th percentiles from the GCM results. Similarly, we could represent the range of the scaling relations derived from the RCMs by two values of $c_{\mathrm{Q}}^{\mathrm{T}}$ and $c_{\mathrm{Q}}^{\text {circ }}$, and by combining these values for the steering parameters and the scaling relations we could construct our scenarios. Besides that this procedure would lead to more than four scenarios, we think that this procedure is not optimal because Eq. 1 is an approximate relation. We use a simple proxy for the circulation only, ignoring for instance changes in the vorticity and the north-south component of the geostrophic wind. In addition, there may be factors that impact on the local climate which are not well sampled

...) represents six results for one RCM with the blue symbols obtained with $\alpha=0.33$ and red with $\alpha=0.66$ (see Appendix C)

in the RCM ensemble (like, for example, North Atlantic SSTs).

With reasonable values of the steering parameters and a selection and/or weighting of the RCMs we aim to establish a set of changes in the different climate indices $Q$ that matches with the range covered by the GCM results. More precisely, the results should match with the changes for the seasonal means in the GCM ensemble. At the same time, the procedure adds information on climate indices that cannot be directly obtained from the GCMs, for example on the wet-day frequency and the extreme precipitation events. This information is added coherently by making use of the same values of the steering parameters and the same selection and weights of RCM results for all climate indices $Q$ within a particular season and scenario.

In Sect. 5.2 we discus the input from the GCMs, and in Sect. 5.3 we use this information to determine the value for the steering parameters and the RCM weights for each scenario. Section 5.4 discusses a final cross check of the scenario values with the GCM results for the seasonal mean temperature and precipi- 
Fig. 9 Scaling relations $c_{\mathrm{Q}}^{\mathrm{T}}$ and $c_{\mathrm{Q}}^{\text {circ }}$ derived from the HadAM3H RCM ensemble (triangles obtained with $\alpha=0.33$ and circles with $\alpha=0.66$; see Appendix C). Shown by the blue cross is the mean, and the 10th, 20th, 80 th, and 90th percentiles of the separate estimates. The green circle and the red times symbol denote the scaling relations used in the $\mathrm{G} / \mathrm{W}$ and $\mathrm{G}+/ \mathrm{W}+$ scenarios, respectively
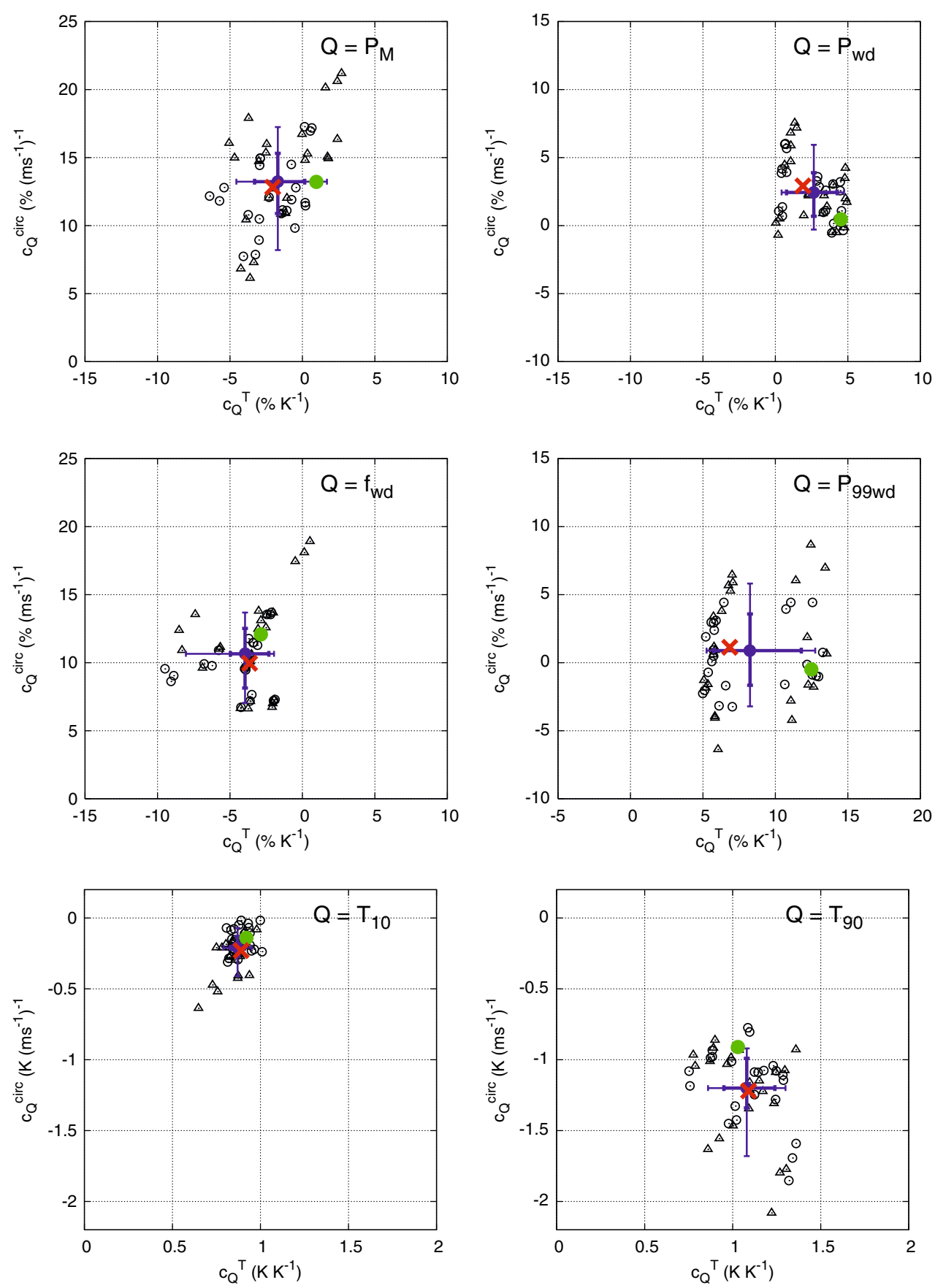

tation change. Results of the scenarios are discussed in Sect. 5.5.

\subsection{Results from the GCMs}

The value for the steering parameter $\Delta T_{\mathrm{g}}$ is estimated in a rather straightforward way from the GCM results. Figure 10 shows the time evolution of the global mean temperature rise compared to 1990 for the selected GCMs using different emission scenarios. Except MIROCHi A1b, all model integrations display a temperature rise between 1.1 and $2^{\circ} \mathrm{C}$. We round these values to 1 and $2^{\circ} \mathrm{C}$ for our scenarios.

The change of the circulation can be considered as a second order response to the global change in the radiation balance, which we measure by $\Delta T_{\mathrm{g}}$. In accordance, we scale $\Delta G_{\mathrm{w}}$ by $\Delta T_{\mathrm{g}}$, and the results are plotted in Fig. 11. This figure is obtained by first applying a 30-year moving average to the yearly time series, and then plotting the filtered time series against each other at 15 years intervals. A general tendency of increasing $G_{\mathrm{w}}$ in winter (stronger zonal flow) and a 
Fig. 10 Mean global temperature rise compared to 1990 in the selected global models using four different emission scenarios

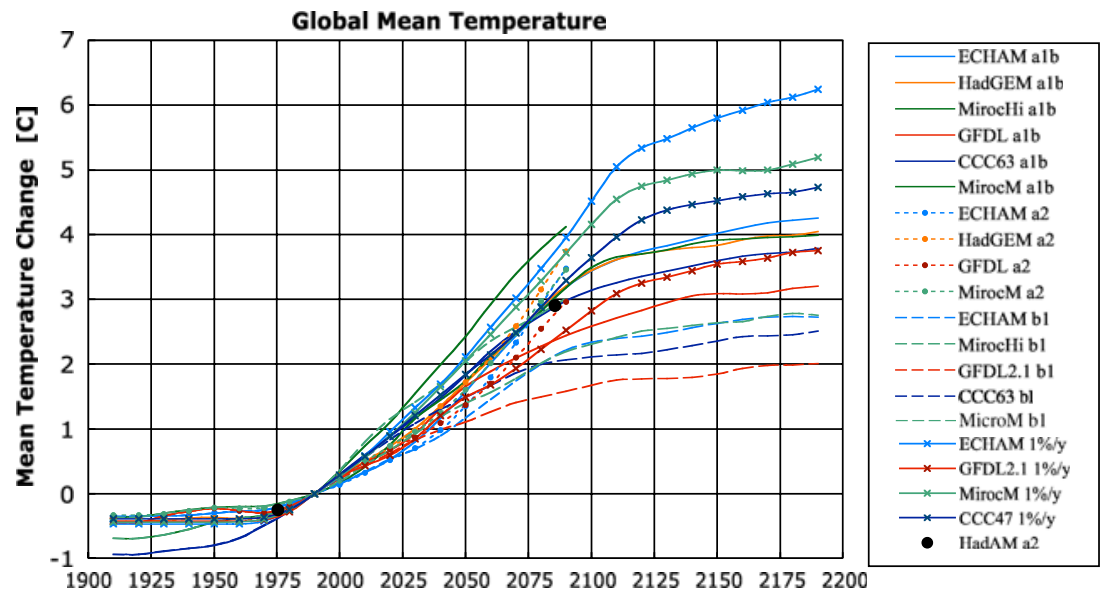

decrease in summer is shown. These trends display a general (quasi-linear) increase with the global temperature, however with a significant variability. We note that each GCM has its own characteristic scaling relation, which is roughly the same for different emission scenarios.

Figure 12 shows the scaling behavior of the mean precipitation interpolated to $51^{\circ} \mathrm{N}, 6^{\circ} \mathrm{E}$ (southeast Netherlands) with the global temperature rise (obtained similar to Fig. 11). The two scaling behaviors for precipitation estimated from Fig. 12 that we will employ in the next section to construct our scenarios are:

- winter: $3 \%{ }^{\circ} \mathrm{C}^{-1}$ with a weak circulation change and $7 \%{ }^{\circ} \mathrm{C}^{-1}$ with a strong circulation change. The value $3 \%{ }^{\circ} \mathrm{C}^{-1}$ is based on MIROCHi and HadGEM which have a weak circulation change in winter. The value of $7 \%{ }^{\circ} \mathrm{C}^{-1}$ is based on ECHAM5 and GFDL2.1 integrations, which are characterized by strong circulation changes in winter (see Fig. 11). We note that the winter is characterized by a significant natural variability, which does not scale with the global temperature rise (see also Giorgi 2005b). Therefore, relatively large deviations from these scaling relations for the GCM data occur, in particular for low $\Delta T_{\mathrm{g}}$.

- summer: $3 \%{ }^{\circ} \mathrm{C}^{-1}$ with a weak circulation change and $-10 \%{ }^{\circ} \mathrm{C}^{-1}$ with a strong circulation change. The value of $3 \%{ }^{\circ} \mathrm{C}^{-1}$ is based on results of CCC63 and MIROCHi which are characterized by weak circulation changes. Note that MIROCHi appears to have a stronger dependency and CCC63 a weaker dependency close to zero. The dependency of $-10 \%$ ${ }^{\circ} \mathrm{C}^{-1}$ is supported by results of HadGEM and ECHAM5. Results of GFDL2.1 even show a stronger reduction of precipitation. The simulation of GFDL2.1 appears rather exceptional with strong changes in the geostrophic vorticity and a very cold Atlantic ocean (UO06). Therefore, the results of GFDL2.1 were considered to be too extreme to be relevant for the scenarios for the Netherlands.

For the scenarios with a weak circulation change, both winter and summer use a scaling of $3 \%{ }^{\circ} \mathrm{C}^{-1}$. This
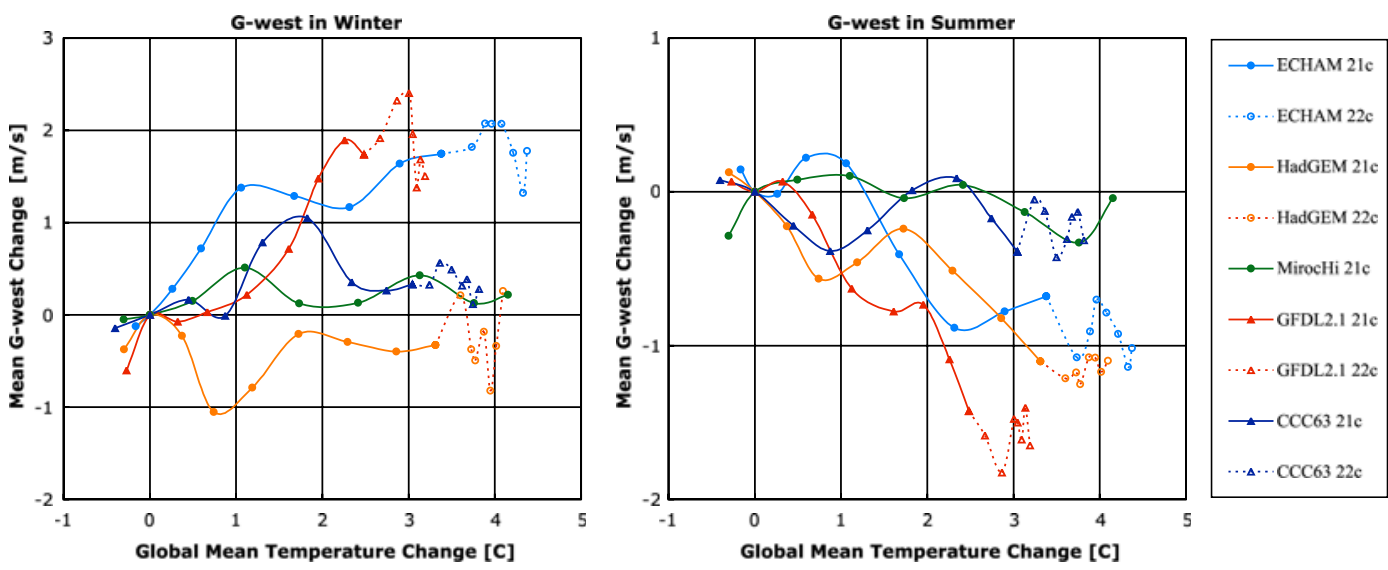

Fig. 11 Change in $G_{\mathrm{w}}$ as a function of global temperature rise in an ensemble of GCM simulations using the A1B emission scenario. The reference period is 1976-2005, and 21c and 22c denote the 21st and 22st century, respectively 
Fig. 12 Similar to Fig. 11, but now for mean precipitation for the GCMs interpolated to $51^{\circ} \mathrm{N}, 6^{\circ} \mathrm{E}$. In addition to the A1B emission scenario, also results with $\mathrm{A} 2$, B1 emissions and a scenario with $1 \%$ /year increase in $\mathrm{CO}_{2}$ are shown. Estimated dependencies that are used for the scenarios are shown by the thick black lines
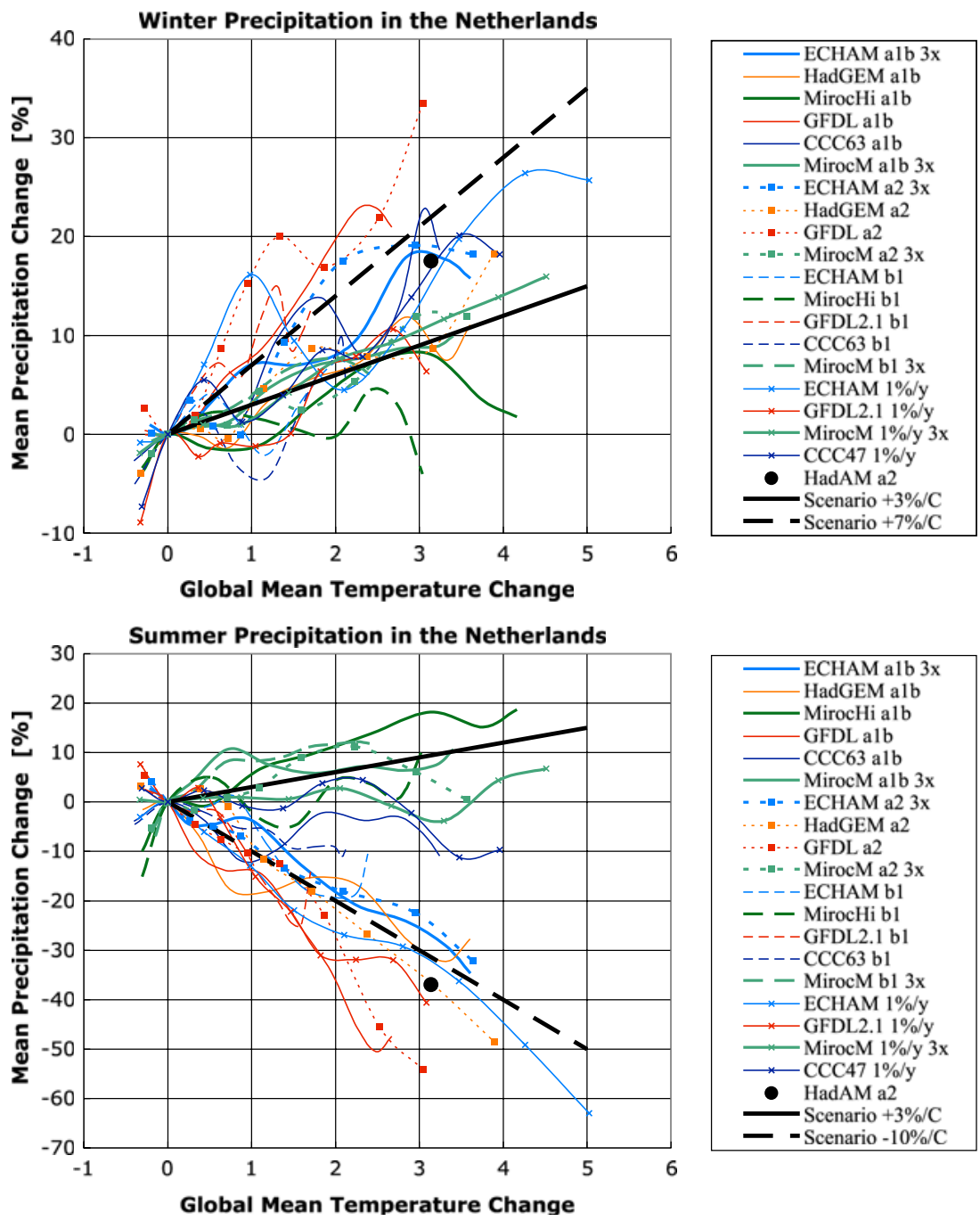

is about half the value as predicted by the ClausiusClapeyron relation. It corresponds reasonably well $2 \%$ ${ }^{\circ} \mathrm{C}^{-1}$ found by Held and Soden (2006) based on scaling of GCM results on a global scale.

\subsection{RCM based downscaling: choice of steering parameter values and model weights}

We present detailed results for two scenarios obtained with $\Delta T_{\mathrm{g}}=2^{\circ} \mathrm{C}$ : one scenario with a weak circulation change labeled as $\mathrm{W}$, and one with a strong circulation change labeled as $\mathrm{W}+$. Two other scenarios, $\mathrm{G}$ and $\mathrm{G}+$, are derived in a similar fashion for $\Delta T_{\mathrm{g}}=1^{\circ} \mathrm{C}$.

For the summer scenarios the precipitation scaling relations based on the GCM ensemble impose $+6 \%$ for $\mathrm{W}$ and $-20 \%$ for $\mathrm{W}+$. Taking the RCM ensemble mean $c_{\mathrm{Q}}^{\mathrm{T}}$ and $c_{\mathrm{Q}}^{\text {circ }}$ for mean precipitation it turns out that we need an unrealistic increase of $G_{\mathrm{w}}$ of $0.7 \mathrm{~ms}^{-1}$ to obtain $+6 \%$. This appears to be related to the fact that most RCMs have a strong tendency for summer drying (Lenderink et al. 2007; Van den Hurk et al. 2005). The spread in the RCM results is also rather large. It therefore makes sense to separate the RCMs in two "groups" based on characteristics of the models:

- For the W scenario (+6 \%) RACMO2 is used. RACMO2 results show a relatively good correspondence to observations of summertime temperature variability (Lenderink et al. 2007), hydrological budgets of the Rhine area (Van den Hurk et al. 2005), and precipitation extremes over the Rhine catchment area (see Fig. 13). RACMO2 has a relatively small tendency for soil drying (Van den Hurk et al. 2005). Using RACMO2 we get a +6 $\%$ precipitation change with $\Delta G_{\mathrm{w}}=0.2 \mathrm{~ms}^{-1}$.

- For the $\mathrm{W}+$ scenario $(-20 \%)$ all other RCM integrations are used, except the RCAO integration driven by ECHAM4 boundaries. The latter integration is excluded because of the very large 


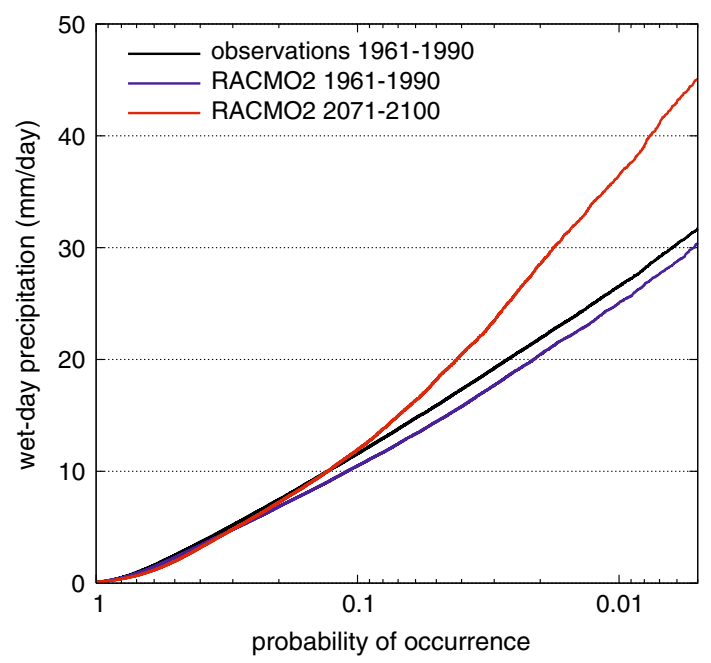

Fig. 13 Extreme statistics of precipitation on a wet-day in RACMO2 compared to observations of the CHR sub-catchments. In this case, we selected RACMO2 grid points in the Rhine catchment area

circulation response in that integration, which makes the separation method prone to large errors. We obtain a value of $\Delta G_{\mathrm{w}}=-1.2 \mathrm{~ms}^{-1}$. The fact that this is slightly low compared to GCM results is most likely caused by the fact that $A_{\mathrm{CEN}}$ is slightly wetter than $A_{\mathrm{DB}}$.

Thus, in the $\mathrm{W}$ scenario a weak circulation change is combined with the results of an RCM (RACMO2) with a weak tendency for continental drying. In the $\mathrm{W}+$ scenario a strong circulation change is combined with the results of the other RCMs with on average a stronger tendency to dry out. The impact of the RCM physics on the mean precipitation change can be estimated as order $5-10 \%$, which is relatively small compared to the circulation related change; for example, RACMO2 using $\Delta G_{\mathrm{w}}=-1.2 \mathrm{~ms}^{-1}$ gives a precipitation change of $-14 \%$ compared to the average of $-20 \%$ in the other RCMs. For extremes the impact of the RCM physics may be much larger; for example for $P_{99 \mathrm{wd}}$ most of the uncertainty is related to the RCM physics. An additional motivation for the choice of these weights is that the clustered behavior of $c_{\mathrm{Q}}^{\mathrm{T}}$ for $P_{99 \mathrm{wd}}$ is explicitly represented in the scenarios, as illustrated by the red and green symbol in Fig. 9.

For winter the GCM scaling relations impose $+6 \%$ for $\mathrm{W}$ and $+14 \%$ for $\mathrm{W}+$. For both scenarios we use the same weighted model ensemble, giving equal weight to the HadAM3H RCM ensemble and the ECHAM4 ensemble. This implies that both ECHAM4 RCM simulations are given a weight 4 (see Table 2). This choice is motivated by the following arguments. In winter much of the climate response is dominated by the large-scale flow dynamics. Unlike summer where differences in the modeling of the hydrological cycle, soil moisture limitations and convective precipitation play an important role, a similar physical reason (except perhaps snow feedbacks, which we consider less important) for RCM model spread is less obvious for the Netherlands. Winter time extreme events are mostly related to synoptic systems, which are strongly forced by the boundaries. This implies that the statistical pooling technique does not add much independent data, and the extreme statistics is strongly determined by the forcing boundaries. We therefore weight the information from both GCM boundaries equally, implying a relatively large weight for the two ECHAM4 RCM simulations. By taking these weights, the influence of the North Atlantic SST originating from the GCM boundary is also weighted equally. We note that $\mathrm{Had} \mathrm{AM} 3 \mathrm{H}$ has a relatively large temperature lag of $2^{\circ} \mathrm{C}$ in the North Atlantic compared to the GCM ensemble (see UO06). With this weighting and the proposed scaling relations, we obtain $\Delta G_{\mathrm{w}}=-0.1 \mathrm{~ms}^{-1}$ for $\mathrm{W}$ and $\Delta G_{\mathrm{w}}=1.0 \mathrm{~ms}^{-1}$ for $\mathrm{W}+$. Both values are within the spread of the GCM ensemble in Fig. 11.

The model weights and the values for the steering parameters are given in Tables 1 and 2. The results for the different climate indices $Q$ are in Table 3.

\subsection{Scenario range in comparison with the GCM ensemble}

Figure 14 shows a cross check of the scenarios with the local GCM output for the seasonal mean change in precipitation and temperature between 1990 (period 1976-2005) and 2050 (period 2036-2065). Because of the inter decadal variability, the difference between 2050 and 1990 in the GCM results is not necessarily representative for the climate change signal. Therefore, we also used two other estimates of the climate change signal, which are obtained by using the change from 1990 to 2060 and to 2070 and then scaling the results by a factor $6 / 7$ and $6 / 8$, respectively. For each GCM an A1b and a B1 emission scenario run is included, thus giving equal weight to a relatively high and a low emission scenario. Only for HadGEM a B1 run was not available. Each estimate is given an equal probability and the cumulative PDF is plotted in Fig. 14. In addition, we plotted the outcome of the four scenarios, assuming an equal probability of each scenario for the purpose of this illustration.

In general, the scenarios values correspond well with the PDF from the GCMs. The range in the scenario values typically covers approximately $70-80 \%$ of the range from the GCMs, which is a large improvement of 
Fig. 14 Changes (2050 compared to 1990) in mean temperature and precipitation obtained from the GCM results (lines) and the scenarios (squares) for the Netherlands. Two additional estimates from the GCM results are given by rescaling the results for 2060 and 2070
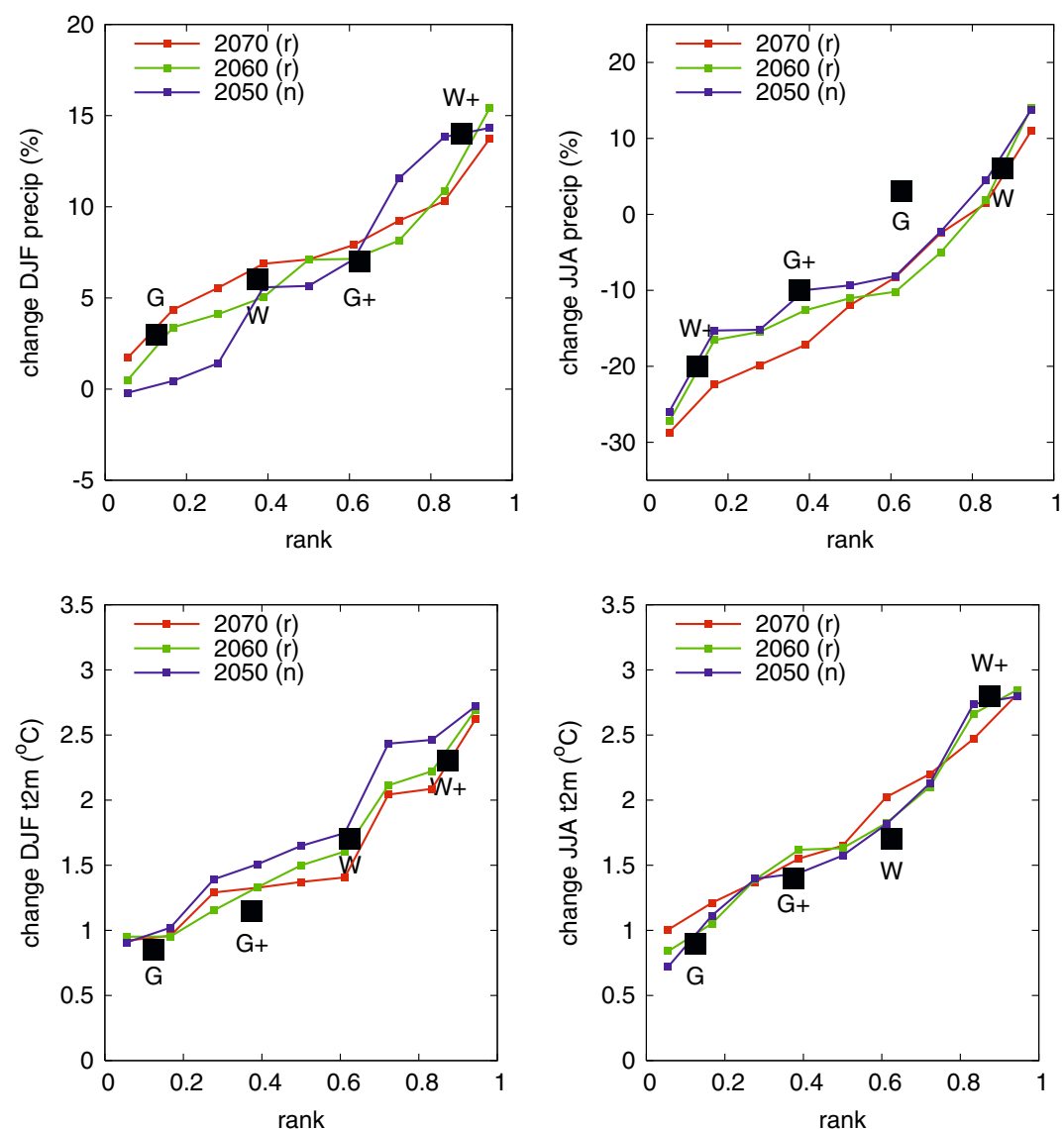

the typical range covered in Fig. 1 for the direct RCM output. For summer precipitation the range covered by the four scenarios smaller, but we note that the extreme tails in the GCM results are related to only two models: MIROCHi for the wet tail and GFDL2.1 for the dry tail. For winter, the lowest scenario of the mean precipitation change, $+3 \%$ in $\mathrm{G}$, appears rather high compared to the GCM results obtained for 2050. However, the value is more in line with the rescaled GCM results for 2060 and 2070. We note that the scenarios are also broadly consistent with the precipitation changes in a much larger ensemble of $204 \mathrm{AR}$

Table 1 Steering parameters and model ensembles

\begin{tabular}{lllllr}
\hline Scenario & Season & $\begin{array}{l}\text { Model } \\
\text { ensemble }\end{array}$ & $\begin{array}{l}\Delta T_{\mathrm{g}} \\
\left({ }^{\circ} \mathrm{C}\right)\end{array}$ & $\begin{array}{l}\Delta G_{\mathrm{w}} \\
\left(\mathrm{ms}^{-1}\right)\end{array}$ & $\begin{array}{r}\Delta P_{\mathrm{m}} \\
(\%)\end{array}$ \\
\hline $\mathrm{G}$ & JJA & RACMO2 & 1.0 & +0.12 & +3 \\
$\mathrm{G}+$ & JJA & ENS-JJA & 1.0 & -0.62 & -10 \\
$\mathrm{~W}$ & JJA & RACMO2 & 2.0 & +0.24 & +6 \\
$\mathrm{~W}+$ & JJA & ENS-JJA & 2.0 & -1.24 & -20 \\
$\mathrm{G}$ & DJF & ENS-DJF & 1.0 & -0.07 & +3 \\
$\mathrm{G}+$ & DJF & ENS-DJF & 1.0 & +0.50 & +7 \\
$\mathrm{~W}$ & DJF & ENS-DJF & 2.0 & -0.14 & +6 \\
$\mathrm{~W}+$ & DJF & ENS-DJF & 2.0 & +1.00 & +14 \\
\hline
\end{tabular}

a Table 2 gives an explanation of the model ensembles used
GCMs (forced with B1, A1b and A2 emissions) as discussed by Giorgi and Bi (2005a, b).

Changes in mean precipitation and mean temperature in a scenario are connected by the underlying use of the steering parameters and model weights. Therefore, it is not straightforward to improve the correspondence of the scenarios with the GCM ensemble PDF; for example, an improvement for mean precipitation might cause a deterioration for mean temperature, and vice versa.

\subsection{Results for other indices and usage}

For the winter, the scenarios span a range of mean precipitation change between $+3 \%$ and $+14 \%$ (see Table 3). The changes in $P_{\mathrm{wd}}$ and $P_{99 \mathrm{wd}}$ closely follow the change of the means. There is a small increase in wet-day frequency in the scenario with strong circulation change, $+2 \%$ for $\mathrm{W}+$. In summer the scenarios span a range between $-20 \%$ and $+6 \%$ mean precipitation change. For the dry scenarios $(\mathrm{G}+$ and $\mathrm{W}+)$ the decrease in mean precipitation is caused by the reduction in the wet-day frequency $f_{\mathrm{wd}}$. The mean precipitation on a wet-day does not change. However, there is a shift in the distribution of precipitation with a 
Table 2 Weight of the different RCM simulations in the different scenarios

a, b Two different integrations of ECHAM4

\begin{tabular}{lllll}
\hline RCM & $\begin{array}{l}\text { Scenario } \\
\text { Ensemble name } \\
\text { Boundary }\end{array}$ & $\begin{array}{l}\text { G/W JJA } \\
\text { RACMO2 }\end{array}$ & $\begin{array}{l}\text { G+/W+ JJA } \\
\text { ENS-JJA }\end{array}$ & $\begin{array}{l}\text { DJF } \\
\text { ENS-DJF }\end{array}$ \\
\hline HIRHAM & HadAM3H-A2 & - & 1 & 1 \\
CHRM & HadAM3H-A2 & - & 1 & 1 \\
CLM & HadAM3H-A2 & - & 1 & 1 \\
HadRM3H & HadAM3H-A2 & - & 1 & 1 \\
RegCM & HadAM3H-A2 & - & 1 & 1 \\
RACMO2 & HadAM3H-A2 & 1 & - & 1 \\
REMO & HadAM3H-A2 & - & 1 & 1 \\
RCAO & HadAM3H-A2 & - & 1 & 4 \\
HIRHAM & ECHAM4-A2 $^{\mathrm{a}}$ & - & 1 & 4 \\
RCAO & ECHAM4-A2 & - & - & 4 \\
\hline
\end{tabular}

Table 3 Results for the scenarios

\begin{tabular}{|c|c|c|c|c|c|c|c|c|}
\hline \multirow[t]{2}{*}{ Scenario } & \multicolumn{4}{|l|}{ DJF } & \multicolumn{4}{|l|}{ JJA } \\
\hline & G & $\mathrm{G}+$ & $\mathrm{W}$ & $\mathrm{W}+$ & G & $\mathrm{G}+$ & W & $\mathrm{W}+$ \\
\hline$\Delta T_{\mathrm{g}}\left({ }^{\circ} \mathrm{C}\right)$ & +1.0 & +1.0 & +2.0 & +2.0 & +1.0 & +1.0 & +2.0 & +2.0 \\
\hline$\Delta T_{\mathrm{m}}\left({ }^{\circ} \mathrm{C}\right)$ & +0.9 & +1.1 & +1.7 & +2.3 & +0.9 & +1.4 & +1.7 & +2.9 \\
\hline$\Delta T_{10}\left({ }^{\circ} \mathrm{C}\right)$ & +0.9 & +1.4 & +1.9 & +2.8 & +0.9 & +1.0 & +1.8 & +2.2 \\
\hline$\Delta T_{50}\left({ }^{\circ} \mathrm{C}\right)$ & +0.8 & +1.1 & +1.6 & +2.1 & +0.8 & +1.4 & +1.6 & +2.8 \\
\hline$\Delta T_{90}\left({ }^{\circ} \mathrm{C}\right)$ & +0.8 & +1.0 & +1.6 & +1.9 & +0.9 & +1.8 & +1.9 & +3.6 \\
\hline$\Delta P_{\mathrm{m}}(\%)$ & +3 & +7 & +6 & +14 & +3 & -10 & +6 & -20 \\
\hline$\Delta P_{\mathrm{wd}}(\%)$ & +3 & +6 & +6 & +12 & +4 & 0 & +9 & 0 \\
\hline$\Delta f_{\mathrm{wd}}(\%)$ & 0 & +1 & 0 & +2 & -1 & -10 & -3 & -20 \\
\hline$\Delta P_{99 \mathrm{wd}}(\%)$ & +4 & +6 & +8 & +12 & +12 & +6 & +25 & +12 \\
\hline
\end{tabular}

greater fraction of the precipitation caused by intense events. $P_{99 w d}$ increases by $+6 \%$ in $\mathrm{G}+$ and $+12 \%$ in $\mathrm{W}+$. The scenarios with weak circulation change are characterized by a strong increase in precipitation on a wet-day, for example $+9 \%$ in $\mathrm{W}$. In addition, there is a much stronger increase in intense events with a change in $P_{99 w d}$ of $+25 \%$. The large change in extremes of $+12 \%{ }^{\circ} \mathrm{C}^{-1}$ and the small decrease in wet-day frequency $\left(-1.5 \%{ }^{\circ} \mathrm{C}^{-1}\right)$ in these scenarios corresponds well with results of MIROCHi. Analysis of 33 grid points near the Netherlands in MIROCHi show a $+10 \%{ }^{\circ} \mathrm{C}^{-1}$ for $P_{99 \mathrm{wd}}$ and $-1 \%{ }^{\circ} \mathrm{C}^{-1}$ for $f_{\mathrm{wd}}$. We note that MIROCHi has a relatively high resolution of approx. $110 \mathrm{~km}$. The other GCMs generally display smaller increases in extreme events of order $5 \%{ }^{\circ} \mathrm{C}^{-1}$, consistent with our $\mathrm{G}+$ and $\mathrm{W}+$ scenarios, but due to the low resolution of these models it is difficult to assess the significance of these results.

For temperature, the mean temperature change in the scenarios span a range between 0.9 and $2.3^{\circ} \mathrm{C}$ in winter, and between 0.9 and $2.9^{\circ} \mathrm{C}$ in summer. The mean daily temperature on cold days in winter $\left(T_{10}\right)$ and the warm days in summer $\left(T_{90}\right)$ warm significantly more than the average change in the $\mathrm{G}+/ \mathrm{W}+$ scenarios.
In summer, $T_{90}$ increases by $3.6^{\circ} \mathrm{C}$ in the $\mathrm{W}+$ scenario, exceeding the global temperature rise by $1.6^{\circ} \mathrm{C}$.

Van den Hurk et al. (2006) further apply the changes in the above climate indices. Additional spatial and temporal information is added by employing simple transformations of station observations using the change in $T_{10}, T_{50}$, and $T_{90}$ for temperature and $f_{\mathrm{wd}}$, $P_{99 \mathrm{wd}}$ and $P_{\mathrm{wd}}$ for precipitation. For example, in the $\mathrm{W}+$ scenario this time series transformation yields an increase of the number of warm days (max. temperature above $25^{\circ} \mathrm{C}$ ) at De Bilt from 22 to 44 days.

\section{Summary and discussion}

In this paper four climate scenarios (labeled by $\mathrm{G}, \mathrm{W}$, $\mathrm{G}+$, and $\mathrm{W}+$ ) are constructed for the Netherlands for the year 2050. Scenarios are constructed for a low $\left(+1^{\circ} \mathrm{C}\right)$ global temperature rise $(\mathrm{G}$ and $\mathrm{G}+)$ and a high $\left(+2^{\circ} \mathrm{C}\right)$ temperature rise $(\mathrm{W}$ and $\mathrm{W}+)$. The " + " scenarios are characterized by a significant circulation change with more easterly winds in summer and more westerly in winter. For each of these scenarios we combined information from global and regional mod- 
els using a conceptual framework of uncertainty as discussed in Sect. 3. With this limited set of scenarios we aim to give a plausible representation of the uncertainty range in climate predictions for the climate of the Netherlands (with uncertainty defined in terms of model spread as discussed in the introduction).

One important part of the process of scenario construction is model selection and weighting, involving decisions based on expert judgment. GCMs were selected based on their ability to represent the circulation statistics over the globe and in particular over Europe (UO06). In summer, RCM weights were set to represent uncertainty in the modeling of the regional hydrological cycle. In winter, the small ensemble of ECHAM4 driven RCM integrations (2 compared to 8 with HadAM3H) is weighted relatively strong.

The method consisted of two steps. First, we separated the climate change signal in the RCM results into a component related to a mean circulation change, and a residual part which we relate to the global temperature change. In the second step, we rescale these terms in order to construct the scenarios. The rescaling is done by employing values of the global temperature rise $\left(\Delta T_{\mathrm{g}}\right)$ and circulation change $\left(\Delta G_{\mathrm{w}}\right.$, west component of the geostrophic surface wind) from the GCM ensemble. Besides the use of the steering parameters $\left(\Delta T_{\mathrm{g}}\right.$ and $\left.\Delta G_{\mathrm{w}}\right)$, uncertainty in physical processes acting on the regional scale are quantified explicitly in the scenarios by means of selection and weighting of the different RCM simulations.

For each scenario the same steering parameters are used for all climate indices, providing consistency between the changes in the different indices-that is, the predicted changes in a scenario could well occur at the same time. This is a big advantage when the application (e.g. impact assessment model) depends on multiple climate indices.

The need for the rescaling arises from the fact that with the limited number of RCM integrations only part of the uncertainty range is sampled (see Fig. 1). Although we feel that the rescaled RCM results can be used rather successfully as a substitute, they clearly do not replace RCM integration under a wider, more realistic range of forcing boundaries. Therefore, this study emphasizes the need for more regional model simulations, in particular with a wider range of circulation changes and the North Atlantic SST changes. In the European project ENSEMBLES (Hewitt and Griggs 2004) a significant number of these integrations will be carried out.

In order to make more accurate climate predictions, the need for a better understanding and modelling of the climate system is clear. For example, we need to improve our modelling of the circulation (Gillett 2005). This requires a better understanding of the (potentially) important processes: large-scale drying over the continent in summer (Pal and Eltahir 2003), poleward extension of the jet stream (Yin 2005), and remote atmospheric tele-connection patterns originating from the tropical ocean (Selten et al. 2004; Hurrell et al. 2004). The interaction between circulation changes and continental drying and snow feedbacks also needs more investigation. A better understanding of the consequences of a higher atmospheric moisture content (Held and Soden 2006) and climate feedbacks impacting on the radiation balance (Bony et al. 2006) is also needed.

Besides these questions concerning understanding and modeling of the climate system, we also posed many methodological questions related to the construction of the scenarios. How do we combine the different sources of information on climate change: the model results of the RCMs and the GCMs, observations, and knowledge about the climate system? For which spatial and temporal scales do we trust the GCM and the RCM results? How do we illustrate uncertainty in a limited set of consistent scenarios? In this paper, we attempted to give answers to these questions. We realize that our answers are based on the current knowledge, and that they may not be generally applicable. But we feel that questioning and answering these type of questions will lead to a better understanding, and eventually, to better predictions of regional climate change.

Acknowledgments The RCM data has been obtained from the PRUDENCE data server (prudence.dmi.dk). In particular, we thank Ole Christensen for his effort to put all these data on the server. We acknowledge the IPCC Program for Climate Model Diagnosis and Intercomparison (PCMDI) for collecting and archiving the GCM data, and Erik van Meijgaard for running and developing RACMO2. The authors thank Gerbrand Komen, Geert-Jan van Oldenborgh, Albert Klein-Tank, and two reviewers for their comments on earlier versions of this manuscript. Part of this work has been financed by Dutch Climate Change and Spatial Planning program (BSIK) and by the European FP-6 project ENSEMBLES (GOCE-CT-2003505539).

\section{Appendix A}

As a simple circulation index we computed the eastwest component of the geostrophic surface wind $G_{\mathrm{w}}$ (positive for westerly winds) from the mean sea level pressure at four corner points $\left(45^{\circ} \mathrm{N} / 0^{\circ} \mathrm{E}, 45^{\circ} \mathrm{N} / 20^{\circ} \mathrm{E}\right.$, $55^{\circ} \mathrm{N} / 0^{\circ} \mathrm{E}$, and $55^{\circ} \mathrm{N} / 20^{\circ} \mathrm{E}$ in Fig. 2). Following UO06 we also considered more complex circulation indices by combing the effects of the east-west and north- 
south components of the geostrophic wind and a measure of the vorticity. These indices were derived by optimizing the explained variance in observations of monthly mean temperature and precipitation (see UO06 for details). It turned out that the explained variance in the PRUDENCE RCM results obtained with $G_{\mathrm{w}}$ were comparable to the explained variance obtained with the combined indices of the flow. Therefore, for means of simplicity we decided to use $G_{\mathrm{w}}$. However, we note that our RCM integrations are characterized by rather small changes in the geostrophic vorticity. For other seasons and other RCM results, obtained with other GCMs as a boundary, one might have to rely on more complex flow indices.

\section{Appendix B}

The fit between a climate index $Q$ and a circulation index $G_{\mathrm{w}}$ is expressed as

$Q_{\mathrm{c}}=a_{\mathrm{c}} G_{\mathrm{w}}+b_{\mathrm{c}}$

$Q_{\mathrm{f}}=a_{\mathrm{f}} G_{\mathrm{w}}+b_{\mathrm{f}}$

with $a, b$ the coefficients to be determined. Subscripts denote the control (c) and future (f) period. These fits are computed for both seasons considered. To keep the text concise we omitted the reference to a season in the following text. The following regression procedures are used:

(a) A simple regression based on yearly data. For each year, $Q$ and the average $G_{\mathrm{w}}$ are computed, and a least square fitting procedure is used to fit the 30 data points. This procedure, however, may be less appropriate to determine the statistics of extremes since each summer or winter consists of only about 90 days (see Fig. 15b).

(b) A (group) regression based on 10-year periods. The 30 years are divided into three 10 -year periods based on the highest and lowest values of $G_{\mathrm{w}}$ and those in the middle. For each 10 -year period $Q$ and $G_{\mathrm{w}}$ are computed and the results are fitted (three data points).

(c) A regression of a synthetic set of resampled 10year climates. A set of 10-year climates with low, average and high values of $G_{\mathrm{w}}$ was generated using a resampling technique. For the set with high $G_{\mathrm{w}}$, we drew 10 years, with replacement, from the 18 years with highest value of $G_{\mathrm{w}}$. This is repeated $N=200$ times. The same procedure is done using the 18 years with average, and 18 years with the lowest value of $G_{\mathrm{w}}$. This gives $3 N$ samples of 10 -year climates. We note that resampling 10 years from the total 30 -year period resulted in a variance in mean $G_{\mathrm{w}}$ in the resampled data set below $0.5 \mathrm{~ms}^{-1}$, so that the dependency on $G_{\mathrm{w}}$ could not be determined. The resampled data is also plotted in Fig. 7 to give a crude impression of the spread of a surrogate 10year climate around the fitted line.

\section{Appendix C}

Using the fits between $Q$ and $G_{\mathrm{w}}$ for the control and the future time slice, the total response is decomposed into a part that is related to the circulation change and a residual part (see Fig. 4). When the slopes of the fits are not equal this splitting involves a rather arbitrary
Fig. 15 Mean precipitation $(P)$ and precipitation extremes $P_{99 \mathrm{wd}}$ in the RCM integrations for the control (squares) and the future (circles) period. Shown are $\langle Q\rangle$ (solid) and $\bar{Q}$ (open symbols) (see Eqs. C1 and C2). Note that in most case the open symbols are practically indistinguishable from the solid ones. For each RCM, the three groups of results refer to the different fitting procedures $(\mathrm{a}, \mathrm{b}$, and $\mathrm{c}$, respectively) as described in Appendix B
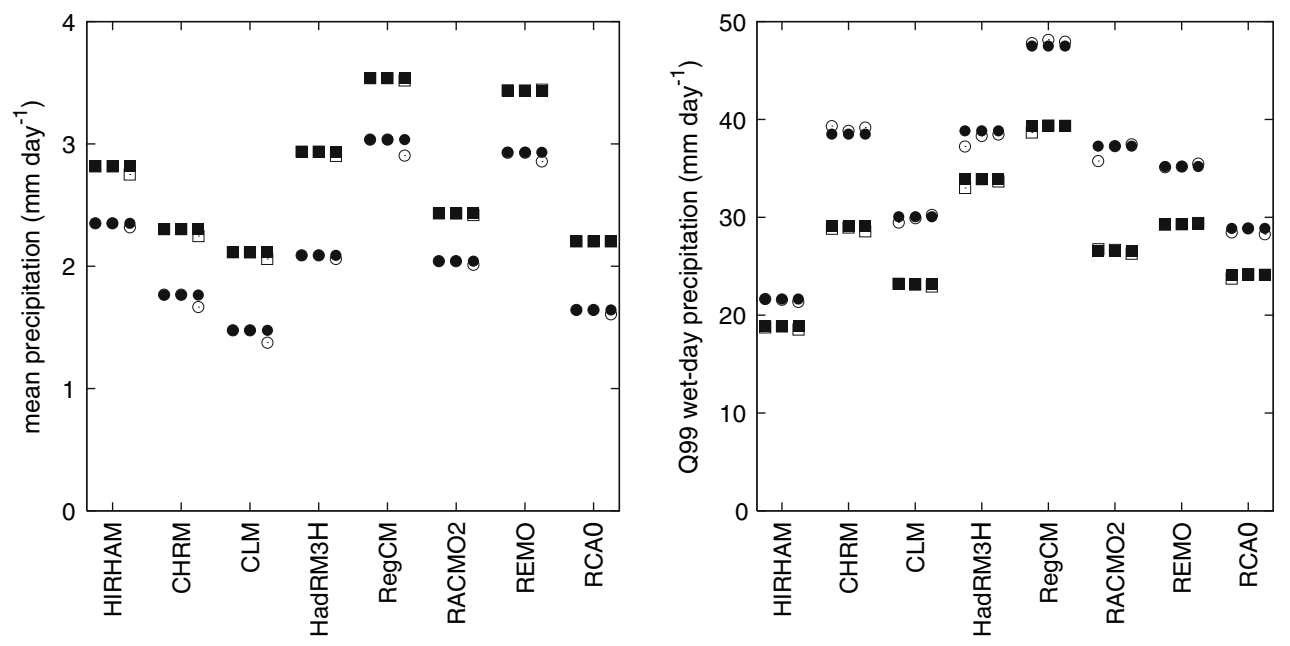
assumption: one could extrapolate the control run forward to the future run, but one could also extrapolate the future run backward to the control. The procedure as described below allows a quantification of the impact of this arbitrary assumption in the calculation.

The mean circulation for the control time slice is defined as $G_{\mathrm{w}, \mathrm{c}}$, the future time slice as $G_{\mathrm{w}, \mathrm{f}}$, and the difference $\Delta G_{\mathrm{w}}=G_{\mathrm{w}, \mathrm{f}}-G_{\mathrm{w}, \mathrm{c}}$. Figure 15 shows that in practice

$$
\begin{aligned}
& \langle Q\rangle_{\mathrm{c}} \cong a_{\mathrm{c}} G_{w, c}+b_{\mathrm{c}} \equiv \bar{Q}_{\mathrm{c}} \\
& \langle Q\rangle_{\mathrm{f}} \cong a_{\mathrm{f}} G_{w, f}+b_{\mathrm{f}} \equiv \bar{Q}_{\mathrm{f}}
\end{aligned}
$$

where $\langle Q\rangle$ is climate index computed for the 30-year time slice. For the mean precipitation the method based on the resampled data shows the largest deviations, but for the precipitation extremes the normal regression based on the yearly values shows the largest errors. Finally we define a reference value of the circulation $G_{\mathrm{w}, \text { ref }}$ where we determine the offset between the two fits:

$$
G_{\mathrm{w}, \mathrm{ref}}=G_{\mathrm{w}, \mathrm{c}}+\alpha \Delta G_{\mathrm{w}}=G_{\mathrm{w}, \mathrm{f}}-(1-\alpha) \Delta G_{\mathrm{w}}
$$

with $\alpha$ between 0 and 1 , which forces $G_{\mathrm{w}, \mathrm{ref}}$ to lie between $G_{\mathrm{w}, \mathrm{c}}$ and $G_{\mathrm{w}, \mathrm{f}}$. Using these definitions, we get

$$
\langle Q\rangle_{\mathrm{f}}-\langle Q\rangle_{\mathrm{c}} \cong \bar{Q}_{\mathrm{f}}-\bar{Q}_{\mathrm{c}}=\Delta Q_{\mathrm{r}}+\Delta Q_{\mathrm{c}}
$$

with

$$
\begin{aligned}
& \Delta Q_{\mathrm{r}}=\left(a_{\mathrm{f}}-a_{\mathrm{c}}\right) G_{\mathrm{w}, \mathrm{ref}}+\left(b_{\mathrm{f}}-b_{\mathrm{c}}\right) \\
& \Delta Q_{\mathrm{c}}=\left(a_{\mathrm{f}}(1-\alpha)+a_{\mathrm{c}} \alpha\right) \Delta G_{\mathrm{w}}
\end{aligned}
$$

The last term $\Delta Q_{\mathrm{c}}$ is the circulation dependent component, which consists of the circulation change multiplied by the effective slope of the control and future integration. The residual term $\Delta Q_{\mathrm{r}}$ is the difference between the two fits at the reference value $G_{\mathrm{w}, \text { ref }}$. For our computations we use $\alpha=0.33$ and $\alpha=0.66$, incorporating part of the uncertainty related to the separation procedure. At the same time $\alpha$ is chosen not too close to zero or one in order to avoid large extrapolations for the data of the control (in case of $\alpha=1$ ) and the future (in case of $\alpha=0$ ) simulation.

\section{References}

Bony S, Colman R, Kattsov VM, Allan RP, Bretherton CS, Dufresne J-L, Hall A, Hallegatte S, Holland MM, Ingram W, Randall DA, Soden BJ, Tselioudis G., Webb M (2006)
How well do we understand and evaluate climate change feedback processes? J Climate 19:3445-3482

Christensen JH, Christensen OB (2003) Climate modelling: severe summertime flooding in Europe. Nature 421:805-806

Christensen JH, Christensen OB (2007) A summary of the PRUDENCE model projections of changes in the European climate by the end of this century. Climatic Change (in press)

Christensen JH, Carter TR, Giorgi F (2002) PRUDENCE employs NEW methods to assess European climate change. EOS 83:147

Déqué M, Rowell D, Lüthi D, Giorgi F, Christensen JH, Rockel B, Jacob D, Kjellström E, de Castro M, Van den Hurk B (2007) An intercomparison of regional climate simulations for Europe: assessing uncertainties in model projections. Climatic Change (in press)

Dessai S, Hulme M (2003) Does climate policy need probabilities? Tyndall Centre Working Paper 34, University of East Anglia Norwich, UK. Available from http://www.tyndall.ac.uk/publications/publications.shtml

Dessai S, Lu X, Hulme M (2005) Limited sensitivity analysis of regional climate change probabilities for the 21st century. J Geophys Res 110:D19108. doi:10.1029/2005JD005919

Emori S, Brown SJ (2005) Dynamic and thermodynamic change in mean and extreme precipitation under climate change. Geophys Res Lett 32:L17706. doi:10.1029/2005GL023272

Gillett NP (2005) Northern Hemisphere circulation. Nature 437:496

Giorgi F(2005a) Climate change prediction. Climatic Change 73:239-265

Giorgi $F(2005 b)$ Interdecadal variability of regional climate change: implications for the development of regional climate change scenarios. Meteorol Atmos Phys 89:1-15

Giorgi F, Bi X (2005a) Regional changes in surface climate interannual variability for the 21st century from ensembles of global model simulations. Geophys Res Lett 32:L13701. doi:10.1029/2005GL023002

Giorgi F, Bi X (2005b) Updated regional precipitation and temperature changes for the 21st century from ensembles of recent AOGCM simulations Geophys Res Lett 32:L21715. doi:10.1029/2005GL0242880

Held IM, Soden BJ (2006) Robust Responses of the hydrological cycle to global warming. J Climate 19(21):5686-5699

Hewitt CD, Griggs DJ (2004) Ensembles-based predictions of climate changes and their impacts (ENSEMBLES). EOS 85:566

Houghton J, Ding Y, Griggs DJ, Nogues M, van der Linden PJ, Dai X, Maskell K Johnson CA (eds) (2001) Climate Change 2001: The scientific basis. Contribution of Working Group I to the Third Assessment Report of the Intergovernmental Panel on Climate Change. Cambridge University Press, Cambridge

Hurrell JW, Hoerling MP, Phillips AS, Xu T (2004) Twentieth century North Atlantic climate change. Part I: assessing determinism. Clim Dyn 23:371-389

Jones PD, Davies TD, Lister DH, Slonosky V, Jonsson T, Bärring Jonsson LP, Maheras P, Kolyva-Machera F, Barriendos M, Martin-Vide J, Rodriquez R, Alcoforado MJ, Wanner H, Pfister C, Luterbacher J, Rickli R, Schuepbach E, Kaas E, Schmith T, Jacobeit J, Beck C (1999) Monthly mean pressure reconstructions for Europe for the $1780 \times 1995$ period. Int J Climatol 19:347-364

Kjellström E, Bärring L, Jacob D, Jones R, Lenderink G, Schär C (2007) Variability in daily maximum and minimum temperatures: recent and future changes over Europe. Climatic Change (in press)

Kors, AG, Claessen FAM, Wesseling JW, Können GP (2000) Scenario's externe krachten voor WB21 (in Dutch). 
WLIDelft Hydraulics and Koninklijk Nederlands Meteorologisch Instituut (KNMI) and Ministerie van Verkeer en Waterstaat and Rijkswaterstaat (RWS) and Rijksinstituut voor Integraal Zoetwaterbeheer en Afvalwaterbehandeling (RIZA) (see also http://www.knmi.nl/climatescenarios/)

Kunkel KE, Pielke R Jr, Changnon SA (1999) Temporal fluctuations in weather and climate extremes that cause economic and human health impacts: a review. Bull Am Meteorol Soc 6:1077-1098

Lenderink G, Van Ulden AP, Van den Hurk B, Van Meijgaard E (2007) Summertime inter-annual temperature variability in an ensemble of regional model simulations: analysis of the surface energy budget. Climatic Change (in press)

Murphy JM, Sexton DMH, Barnett DN, Jones GS, Web MJ, Collins M, Stainforth DA (2004) Quantification of modelling uncertainties in a large ensemble of climate change simulations. Nature 430:768-772

Nakicenovic N, Alcamo J, Davis G, de Vries B, Fenhann J, Gaffin S, Gregory K, Grübler A, Jung TY, Kram T, La Rovere EL, Michaelis L, Mori S, Morita T, Pepper W, Pitcher H, Price L, Raihi K, Roehrl A, Rogner H-H, Sankovski A, Schlesinger M, Shukla P, Smith S, Swart R, van Rooijen S, Victor N, Dadi Z (2000) Emission scenarios. A Special Report of Working Group III of the Intergovernmental Panel on Climate Change. Cambridge University Press, Cambridge, pp 599

Pal JS, Eltahir EAB (2003) A feedback mechanism between soilmoisture distribution and storm tracks. Q J R Meteorol Soc 129:2279-2297
Selten FM, Branstator GW, Dijkstra HA, Kliphuis M (2004) Tropical origins for recent and future Northern Hemisphere climate change. Geophys Res. Lett 31:L21205. doi:10.1029/ 2004GL020739

Van den Hurk B, Hirschi M, Schär C, Lenderink G, Van Meijgaard E, Van Ulden A, Rockel B, Hagemann S, Graham P, Kjellström E, Jones R (2005) Soil control on runoff response to climate change in regional climate model simulations. J Climate 18:3536-3551

Van den Hurk B, Klein-Tank A, et al (2006) KNMI climate change scenarios 2006 for the Netherlands. Scientific Report WR-2006-01, Royal Netherlands Meteorological Institute (available online http://www.knmi.nl/climatescenarios/)

Van Ulden AP, Van Oldenborgh GJ (2006) Large-scale atmospheric circulation biases in global climate model simulations and their importance for climate change in Central Europe. Atmos Chem Phys 6:863-881

Van Ulden AP, Lenderink G. Van den Hurk B, Van Meijgaard E (2007) Circulation statistics and climate change in Central Europe: PRUDENCE simulations and observations. Climatic Change (in press)

Vidale PL, Lüthi D, Wegmann R, Schär C (2007) European climate variability in a heterogeneous multi-model ensemble. Climatic Change (in press)

Yin JH (2005) A consistent poleward shift of the storm tracks in simulations of 21 st century climate. Geophys Res. Lett 32:L18701. doi:10.1029/2005GL023684 